\title{
Analytische High Tech: Ist der unternehmerische Mut in der Schweiz auf der Strecke geblieben und kann er überhaupt noch reaktiviert werden
}

Die bemerkenswerten Fortschritte der analytischen Chemie sind in den letzten vierzig Jahren durch die Instrumentalanalytik erzielt worden. Diese hatte sich als Wirtschaftszweig aus einem Nischengeschäft mit Jahresumsätzen im Millionen Dollarbereich in ein weltweites Multimilliarden Geschäft durchgemausert. Die analytischen Instrumente erwiesen sich dabei als derart attraktiv, dass eine grosse Zahl von Instrumentenherstellern sich in dieser Sparte etablieren konnten. Manch eine Garagenoperation, wie Hewlett-Packard und Beckman Instruments, hat sich in weniger als 50 Jahren aus einem gewerblichen Unternehmen, das bei null anfing, in eine multinationale, weltweit erfolgreiche Firma entwickelt. Die Spitzenreiter sind neben der Instrumentalanalytik konsequenterweise auch auf andern Geschäftszweigen, wie etwa der Computerindustrie, gross geworden, und ein Teil ihres Erfolges ist auf den durch diese Konstellation hervorgerufenen Synergismus von Instrumentenentwicklung und Computertechnik zurückzuführen. Insbesondere amerikanische und später auch japanische Firmen haben die Gelegenheit rechtzeitig genutzt und mit Erfolg das analytische Geschäft betrieben, während die Europäer und damit auch die Schweizer den rechtzeitigen Einstieg verpasst haben. Wo europäische Ansätze bestanden haben, wurden die entsprechenden Unternehmen häufig von amerikanischen Giganten aufgekauft, so Hupe-Busch von Hewlett-Packard und die Bodenseewerke in Überlingen von PerkinElmer USA u.a.m.

Durch die Fortschritte der Instrumentalanalytik wurde das Spektrum der analytisch erfassbaren Substanzen beständig erweitert, was andererseits auch das Geschäft anwachsen liess. Die Instrumentalanalytik drang durch die Chromatographie und modernsten spektroskopischen Methoden, wie
Massenspektrometrie und Kernresonanz immer mehr in die organische Chemie ein. Sie überschritt dábei in den letzten zehn Jahren die Grenze zwischen Chemie und Biologie. Längst kann eine analytische Biologie mit den wichtigsten Teilgebieten analytische Biotechnologie und analytische Molekularbiologie definiert werden. Sie unterscheidet sich zwar in den Anwendungen, nicht aber in den Methoden, von der eigentlichen analytischen Chemie.

Die grossartigen Fortschritte, die gegenwärtig zum besseren Verständnis der Funktion biologischer Zellen erzielt werden, beruhen zum Teil darauf, dass die Dynamik dieser Zellen und ihr Metabolismus analytisch untersucht werden können. Ein offensichtliches Resultat dieser Entwicklung ist die Tatsache, dass sich in neuster Zeit auch in der Biologie scharf erfassbare Daten an wachsenden Kulturen ermitteln und reproduzieren lassen, was allen Merkmalen einer exakten Wissenschaft entspricht, ein Status, den die Chemie und Physik schon lange innehaben. Wissenschaftlich beherrschbar, kann die Biologie/Biotechnologie in Kombination mit analytischen Untersuchungen als Wissenschaft vermehrt in den Dienst der Menschheit gestellt und auch wirtschaftlich genutzt werden.

Das Rezept des wirtschaftlichen Erfolges der Instrumentalanalytik bestand darin, dass ingenieurwissenschaftliches Know-how und physikalische Prinzipien mit der analytischen Methodik verbunden wurden und daraus eben das analytische Instrumentarium, wie etwa der Chromatograph oder das Massenspektrometer entstand, die der Physikochemiker und später der Analytiker in ihrem Interessegebiet erfolgreich einzusetzen wussten. Schlüsseltechnologien waren dabei vor allem die Vakuum- und Pumpentechnik, die mittlerweile einen Stand der Technik erreicht haben, der kaum noch wesentlich

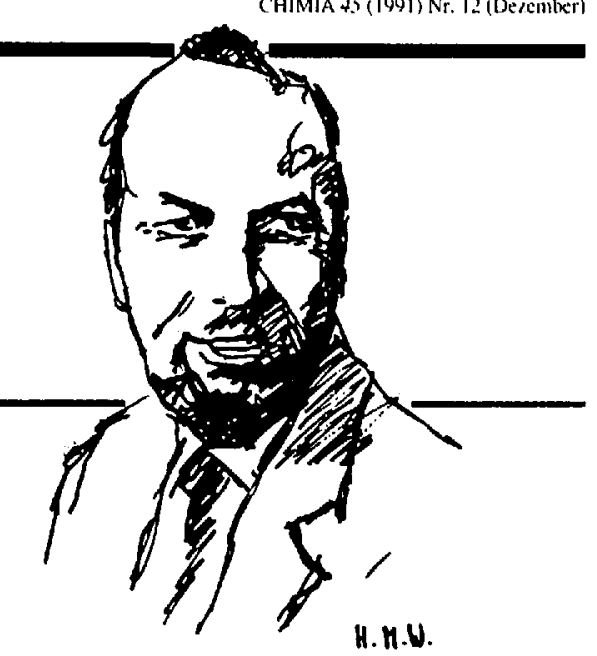

H.H.U.

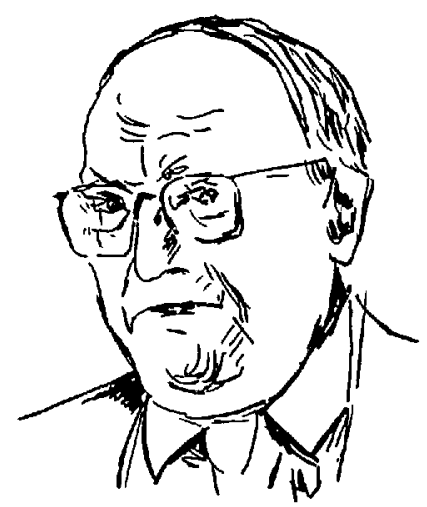

Branco Weiss, 1929 geboren, studierte an der ETHZïrich Chemie. Er gründete seine erste Unternehmung 1956, fünf Jahre nach seinem Diplomabschluss als Ingenieur-Chemiker. Er leitet seitdem mehrere HighTech Unternehmen und ist Lehrbeauftragter an seiner ehemaligen Hochschule.

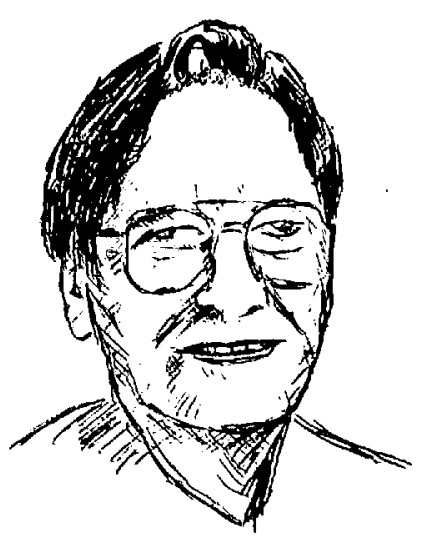

Armin Fiechter, 1924 geboren studierte an der ETHZürich und promovierte 1954 mit einem mikrobiologischen Thema. Nach sechsjähriger Praxis kehrte er an die ETH zuruick und baute dort eine biotechnologische Arbeitsgruppe auf. Er wurde 1969 zum Professor gewählt, gründetc 1982 das Institut für Biotechnologie ETH und hat mit biologischen und bioverfahrenstechnischen Programmen zur Förderung der Leistungssteigerung in Bioprozessen beigetragen. 

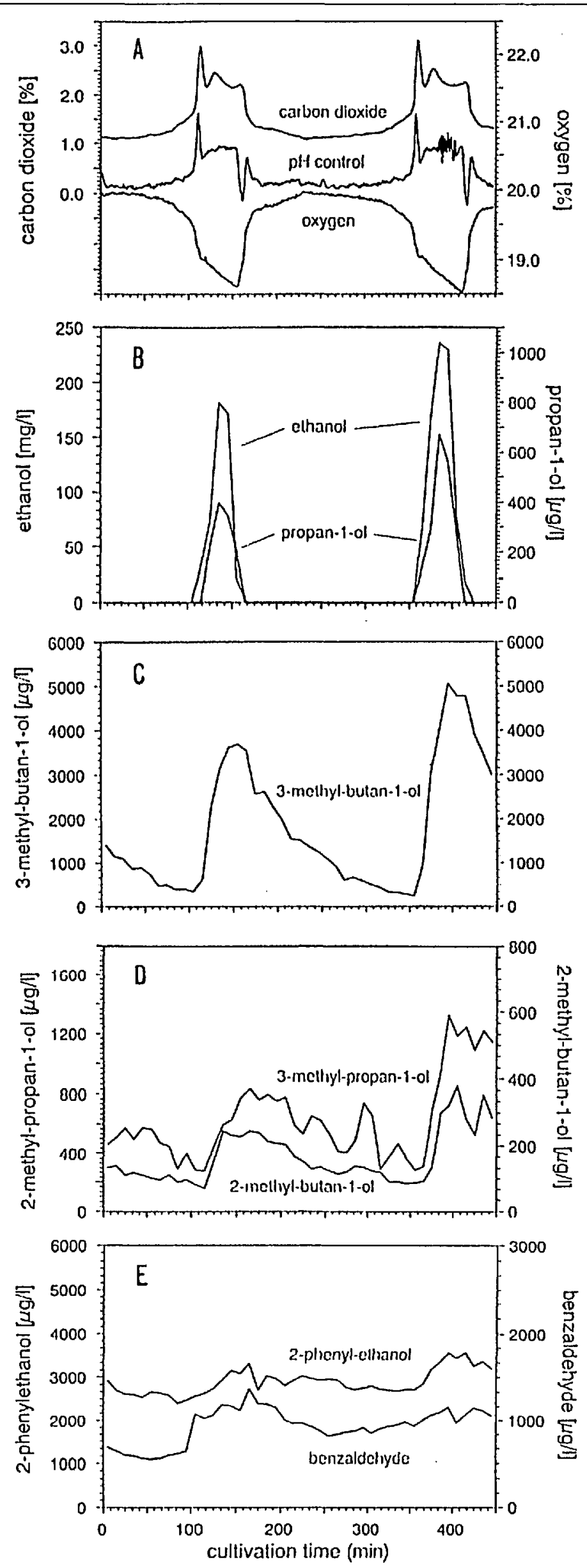

Fig 1. Analytik entlang einem Zell-yklus erzeugt durch stationäre Synchronisation (Saccharomyces cerevisiae). A) Zustandsvariable, wie $\mathrm{CO}_{2}, \mathrm{pH}$-Reglerausgangssignal und $\mathrm{PO}_{2}$, online und kontinuierlich ermittelt (nach Thomas Münch, Bernhard Sonnleitner und Armin Fiechter, ETH Zürich). B-E) Chemische Zustandsvariable, wie Ethanol, höhere Alkoholc und Benzaldehyd, simultan ermittelt mit einem auf der Gaschromatographie aufgebauten TAS (nach Gerhard Kresbach, Ciba-Geigy AG, Basel).

Mit Hilfe derartiger Messungen ist es möglich, beispielsweise den Zellzyklus abzuklären und festzustellen, welche Metaboliten durch chemische Mediumszusätze (z.B. Nutrients) beeinflussbar bzw. nicht beeinflussbar sind. Wie ersichtlich, ergibt sich im vorliegenden Falle eine Zykluszeit von ca. $250 \mathrm{~min}$ verbessert werden kann, übertreffbar nur noch durch allfällige zukünftige Technologien und deren Quantensprünge. Allerdings beginnt sich die Analytik in einer anderen Entwicklungsrichtung zu bewegen, welche an den Hersteller neue Anforderungen hinsichtlich Chemie und Biologie, stellt. Der neue Trend weist in Richtung eines totalen chemischen Analysensystems, das auf wenigen neuartigen Prinzipien beruht, nämlich der Analytik in fliessenden Systemen. Er führt zur Entwicklung von Totalen Analysensystemen (TAS), mit miniaturisierten Strukturen und chemischen oder biologischen Erkennungsprinzipien. Letztere bilden die Voraussetzung für eine neue $\mathrm{Ge}$ neration von Detektoren und chemischen Sensoren und Biosensoren. In der Folge benutzen wir den Begriff 'Analytisches System' bewusst, um dieses vom 'Analytischen Instrument' zu unterscheiden.

Ein miniaturisiertes totales Analysensystem (mini-TAS) bedarf keiner konventionellen Pumpe mehr, denn die fliessenden Systeme, mit Flüssen im Bereich von $\mu \mathrm{l}$ und nl pro min, werden durch chemische Pumpen (z.B. elcktroosmotische Pumpe) erzeugt. Die Analysensysteme werden nicht mehr abschliessend durch ingenieurwissenschaftliche Innovationen, sondern durch chemische Behandlung geschaffen, beruhen auf neuen Werkstoffen (Materialforschung) und bestehen aus neuen chemisch erzeugten Strukturen (Photolithographie, Ätzung, etc.). Die chemische Innovation tritt daher in den Vordergrund der modernen Analysensysteme. Sie stellen Produkte der Synergie von Chemie, Biologie und analytischen Wissenschaften dar. Die neue Analytik, verkörpert durch das TAS, hat sich aus einer retrospektiv wirkenden in eine diagnostizierende Wissenschaft entwickelt, aus der kommerzialisierbare Produkte lanciert werden können, die sich auf der chemischen und biologischen Expertise begründen.

Die moderne Analytik ist eigentlich eine chemische Metrik oder Metrochemie geworden, die ihre Aussage auf der raschen Erkennung von chemischen und biologischen Eigenschaften begründet, und daher eine chemisch-biologische Diagnostik darstellt. Wir verwenden hier den Begriff Diagnostik im weitesten Sinne und nicht nur auf die medizinische Anwendung beschränkt.

Die heutige Gesellschaft und die ihr dienende Technik benötigt diagnostische Aussagen in der Medizin, Pharmazie, Pharmakokinetik und Klinik, aber auch im Umweltschutz, in der Biotechnologie, der chemischen und biologischen Produktion, Nahrungsmittelindustrie, in der Forensik, und nicht zuletzt in der guten alten Qualitätskontrolle.

In Fig. 1 sind eine analytische Überwachung und Regelung eines biotechnologischen Ablaufes illustriert, ein Beispiel für eine angewandte chemisch-biologische Diagnostik in einem sich stetig ändernden, aber jetzt steuerbaren Prozess-System. 


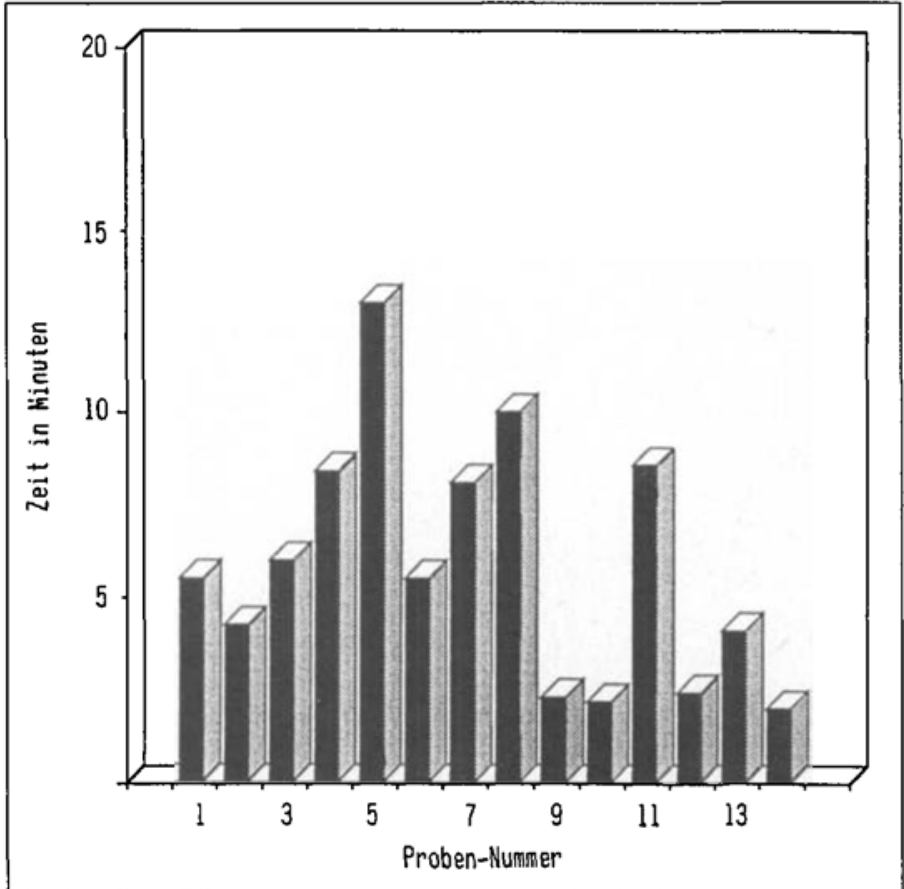

Fig. 2. Zeillicher Aufwand, inklusive Probenaufhereitung beim massenspektrometrischen Screening von unterschiedlichen, aber komplex zusammengesetzten, hochmolekularen biologischen Proben mittels LDI/TOF-MS (Canyon Creek Instruments MassMonitor LDI-1700), ausgefiuhrt von einem Chemielahoranten ohne massenspektrometrische Spezialausbildung (Urs Rindisbacher, Ciba-Geigy AG, Basel)

Viel Neues wurde auf der Suche nach diagnostischen oder 'real time'-Systemen erreicht. In der Arbeitshygiene und im Umweltschutz sind bereits diagnostische Überwachungsgeräte bekannt, und diese werden seit mehr als einem Jahrzehnt routinemässig eingesetzt. Durch die Bedürfnisse der Biologen sind nicht nur Methoden entwickelt worden, die die rasche analytische Untersuchung von extrem grossen Molekülen mit Massen, die Vielfache von 100 $k$ Dalton erreichen, sondern auch eine effizientere und raschere Untersuchung in der eher traditionellen chemischen Diagnostik und dem Screening gestatten. In Fig. 2 und 3 werden Beispiele dieser Tendenz gezeigt, die demonstrieren, dass heute schon solche benutzerfreundliche Analysensysteme existieren. Es müssen aber noch gewaltige analytische Anstrengungen gemacht werden, um eine 'real-time' Diagnostik auf dem Gebiet der Biopolymeren erfolgreich betreiben zu können. Soll zum Beispiel die ambitiöse Sequenzierung der Human Genome Organization (HUGO) erfolgreich abgeschlossen werden, so müssen genau in der so verstandenen Diagnostik in kurzer Zeit noch bedeutende Fortschritte erzielt werden. Man muss analytische Systeme anbieten, die der Biologe und chemische Synthetiker selber bedienen könnten. Diese Wissenschafter dürfen schon aus Zeitgründen nicht mehr auf die Fachkenntnis eines analytischen. Spezialisten zurückgreifen müssen, wenn es darum geht, das analytische Screening an den in grosser Zahl anfallenden Proben durchzuführen. Hohe Benutzerfreundlichkeit ist ein wesentliches Merkmal der neuen Analysensysteme.

Es ist pikant festzustellen, dass die neusten Analysenmethoden wie etwa die Kapil-

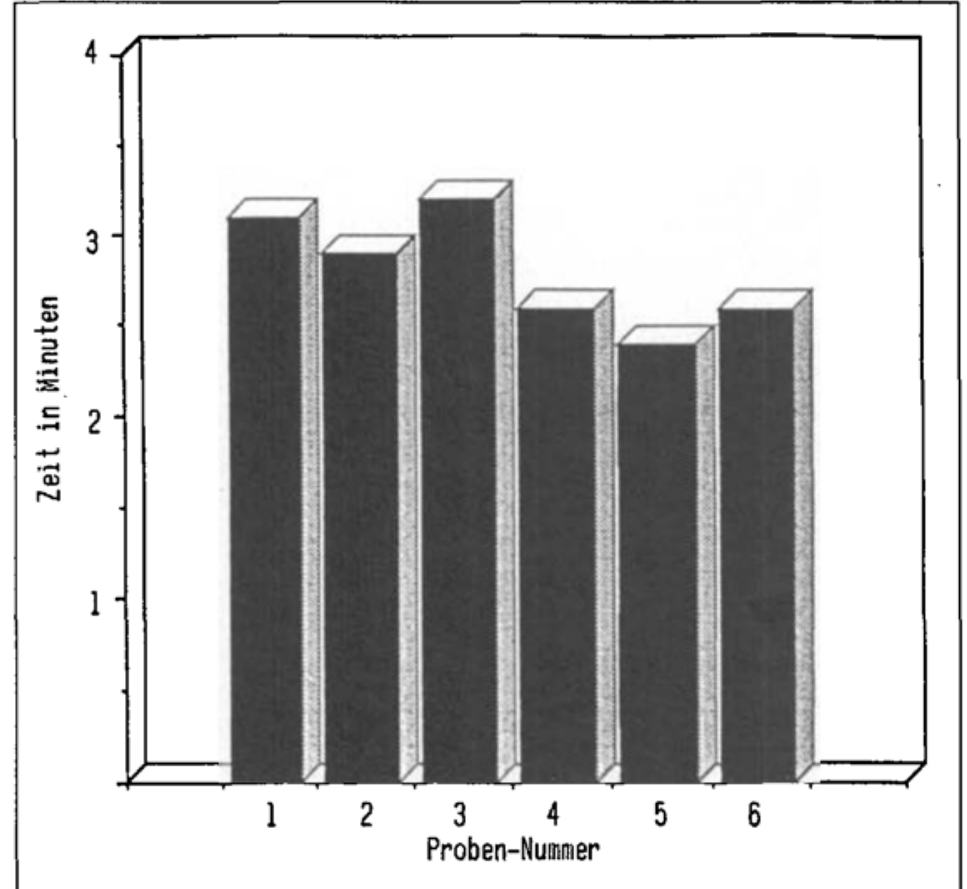

Fig. 3. Zeitlicher Aufu'and, inklusive Probenaufbereitung beim massenspektrometrischen Screening mittels LDIITOF-MS (Canyon Creek Instruments MassMonitor LDI1700) von komplexen Peptidproben, ausgeführt von einem Chemiclahoranten oline massenspektrometrische Spezialaushildung (Urs Rindishacher, Ciba-Geigy AG. Basel) larelektrophorese (CE) und die matrix-unterstützte Laser-Desorption-Ionisation Massenspektrometrie (LDI-MS) sich in Europa wesentlich rascher und erfolgreicher einführen lassen als in den USA, wo aber die ersten Geräte dieser Technologien kommerzialisiert wurden. Eine ähnliche Entwicklung ist auch für die Supercritical Fluid Chromatography (SFC) zu verzeichnen, die heute beispielsweise in Basel an der Applikationsfront der chemischen Industrie - es sei als leuchtendes Beispiel die Pharmaanalytik der Ciba-Geigy $A G$ erwähnt - in zunehmendem Masse in die alltäglichen Untersuchungen eingeführt wird. Die verantwortlichen Analytikmanager haben gelernt, dass hier eine äusserst wirtschaftliche Technologie vorliegt, die bedeutende Effizienzsteigerungen erlaubt. Dies, obwohl das ideale SFC-Gerät auf dem kommerziellen Markt immer noch fehlt und in der restlichen Welt die Nützlichkeit der SFC immer noch zur Debatte steht. Diese letztere Tatsache belegt nur unsere Aussage, dass die heutigen Instrumentenhersteller mit ihrem auf Ingenieurwissenschaften und physikalischen Prinzipien beruhenden Know-how auch Entwicklungen vorantreiben, die am wahren Bedürfnis der Chemie vorbeizielen, und die chemische Industrie dem zukünftigen Analysensystemmarkt sehr viel nähersteht als heute noch allgemein beurteilt und vermutet wird.

Es ist vorauszusehen, dass dank der Anpassungsfähigkeit der neuen Analysensysteme die praktische Problemlösung in den Vordergrund tritt. Infolge der Praktikabilität, die die modernen Analysensysteme auszeichnet, wird die Anwendung enorm erweitert werden können, und der Markt wird einen beachtlichen Aufschwung neh- men. Vom Milliarden-Dollargeschäft von heute wird ein Mehrfaches eines Zehnmilliarden-Dollargeschäftes von morgen entstehen.

Obwohl die Schweiz in der Anwendung der Instrumentalanalytik stets eine Pionierrolle einnehmen konnte, hat es mit ganz wenigen Ausnahmen am unternehmerischen Mut gefehlt, bei der Kommerzialisierung der Analysengeräte mitzumachen, der rechtzeitige Einstieg ist nicht beachtet worden. Und es gibt Anzeichen, dass zu Beginn der90er Jahre einmal mehreine echte Chance der neuen Analytischen Chemie in der Schweiz verpasst wird.

Die Zeit zum Einstieg in den neuen Analysensystemmarkt wäre nun wieder da. Denn immer noch bauen die amerikanischen und japanischen Giganten der Gerätehersteller auf das analytische Instrument von gestern, und sie nehmen die Chance des sich abzeichnenden Trends zum problemlösenden Analysensystem von morgen noch nicht ernsthaft wahr.

Diese ungewöhnliche Situation würde einer sich der Umstände bewussten Firma eine seltene Chance anbieten, erfolgreich einzusteigen, klein anzufangen und rasch zu wachsen. Ein nicht zu unterschätzender Vorteil eines solchen Vorgehens läge im Umstand, dass die Entwicklungen der analytischen Chemie derart rasant verlaufen, dass eine Systemgeneration die vorhergehende schon nach drei bis vier Jahren ablöst; Entwicklungen also erstaunlich rasch in klingende Münze umgesetzt werden könnten, sofern neben den Entwicklungsanstrengungen auch solche des konsequenten Marketings unternommen würden. In der Tat eine Herausforderung, die an die Anfänge der mutigen und erfolgreichen Unterneh- 
menskultur der Schweiz in der Chemie, Maschinen- und Uhrenindustrie erinnert.

Es gab einmal geachtete Schweizer Vorväter der heutigen Industrie, die den unternehmerischen Mut aufbrachten und zur Tat schritten. Mindestens sollte der Wille vorhanden sein, diese Werte aus der Pionierzeit (der chemischen Industrie) verteidigen zu wollen. Die industrielle Gesellschaft wurde in Europa begründet und die Spezialitätenchemie hat ihre Heimat in der Schweiz. Die Schweiz stellt einen Fokussierungspunkt im Gebiet der Chemieexpertise dar, dazu gehört im ausgesprochenen Masse auch die chemische Analytik. Wir haben anderswo aufgezeigt, dass die weltweit grösste Dichte analytischer Anwendungsexpertise im 'Rhine Valley', und ganz speziell in Basel liegt. Beispielsweise wissen wir in der Schweiz, wo die Schwachstellen der chemischen Sensoren und Biosensoren liegen und wir besitzen die Konzepte, um diese Schwächen zu eliminieren, so dass nicht nur deren Einsatz in der Schweiz nahezu ideal wäre, sondern auch die Sensorforschung und -Entwicklung, aber auch die Kommerzialisierung im Standort Schweiz ideale Voraussetzungen finden würde. Auch das Kapital zur Finanzierung von Unternehmen wäre in der Schweiz vorhanden, aber vielfach ziehen die Schweizer Investoren ein Engagement in den USA vor, weil dort Ideen schneller und konsequenter realisiert werden als bei uns.

Die moderne Analytik ist gekennzeichnet durch ein ungewöhnliches Innovationstempo. Wäre es die Absicht, in der neuen Analytik kommerziell mitzuhalten, müssten Massnahmen ergriffen werden, dieses Innovationstempo zu halten. Die Forschung und Entwicklung der analytischen Spitzentechnologie müsste gefördert werden, vorerst an der Hochschule. Die schweizerischen Hochschulen haben immer noch einen guten internationalen Ruf und es bestehen Zusammenarbeitsprojekte mit ausländischen Schulen. Schweizer Postdoktoranden sind in den USA und andern Überseeländern, aber auch an europäischen Hochschulen gerne gesehen, weil sie als tüchtig und gut ausgebildet gelten. Es wäre aber auch eine Zusammenarbeit innerhalb der Schweiz zwischen Hochschule und Industrie nötig. Mit der zur Diskussion stehenden Bildung von Technologieparks in der Schweiz und der Bildung von Schwerpunktszentren in der Forschung ist ein gangbarer Weg aufgezeichnet. Aber machen da die Stärksten der Starken auch wirklich mit?

Es stellt sich somit die Frage, ob nicht im Schosse der schweizerischen Spezialitätenchemie der zur Kommerzialisierung der neuen Analysensysteme benötigte frische Unternehmergeist und Mut aufgebracht werden könnte?

Die von uns beschriebenen Analysensysteme beruhen auf der chemischen und biologischen Expertise und Erfahrung, wie sie in der schweizerischen Spezialitätenchemie und den schweizerischen Hoch- schulen seit langem gepflegt wurden. Sie sind aber ebenso von Innovation getragen und stellen 'value added' Produkte dar, die zur Lösung von vermehrt auf unsere Gesellschaft zukommende Probleme eingesetzt werden können, ohne dass dabei Spezialisten benötigt werden. Diese Analysensysteme sind modular aufgebaut und der auf die spezifische Anwendung getrimmte chemische Teil (z.B. der Chemo- oder Biosensor) ist leicht austauschbar und billig. Der daraus resultierende flexible und rasche Einsatz unterscheidet die Analysensysteme von den konventionellen analytischen Instrumenten.

Die anvisierten Analysensysteme müssen in der chemischen Industrie zur Erhöhung der Wirtschaftlichkeit, zur Schonung der Umwelt und Steigerung der Betriebssicherheit vermehrt eingesetzt werden. Somit besteht eine Rückkopplung von Anwendererfahrung zur Weiterentwicklung von zukünftigen Generationen der Analysensysteme.

Das daraus resultierende Geschäft wird vorerst ein Nischengeschäft sein, das dann aber rasch wachsen kann. Es sollte daher auf ein ganz spezielles Anwendungsgebiet fokussiert werden, wie etwa auf die diagnostizierende analytische Biotechnologie, den angewandten Umweltschutz oder die klinische Diagnostik, von woes innerhalb weniger Jahre in andere Bereiche expandieren und zu einem Geschäft anwachsen wird, das in der Grössenordnung von Pfeilergeschäften der chemischen Industrie liegt.

Wenn es uns gelänge, die erkannten Schwachstellen in Stärken umzuwandeln, wie dies die Industriepioniere im rohstoffarmen Schweizerlande verstanden hatten, und wir imstande wären, mit unternehmerischem Weitblick und Mut, die der Schweiz auf den Leib geschriebenen Vorteile und Expertisen wirtschaftlich zu nutzen, dann könnten wir zuversichtlich in die Zukunft blicken. Die Frage des Standortes Schweiz als Produktionszentrum könnte mit solchen Aktivitäten begründet bejaht werden, und es würde nicht mehr darum gehen, ob wir den Zug verpassen oder nicht, sondern wir würden selbst bestimmen, in welcher Klasse in diesem Zug wir im Jahre 2000 und danach sitzen werden.

Wir danken Herrn Dr. Otto Smrekar für die sorgfältige Durchsicht und Korrektur des Manuskriptes.

Eingegangen am 20. November 1991 


\section{Prelog-Vorlesung 1991 und Festkolloquium aus Anlass des 85. Geburtstages von Professor Vlado Prelog}

Die sechste Prelog-Vorlesung am Laboratorium für Organische Chemie der ETH-Zürich fand am 18. November aus gegebenem Anlass in einem besonderen Rahmen statt. Das war wohl ein Grund dafür, dass der grösste Hörsaal der chemischen Laboratorien nicht alle Zuhörer fassen konnte und eine Fernseh-Übertragung in einen weiteren Raum nötig war. Wie der Vorsteher des Laboratorium, Prof. D. Seebach, in seiner Begrüssung feststellte, kann Prof. Prelog in diesem Jahr gleich eine ganze Reihe ungewöhnlicher Jubiläen feiern: ausser seinem 85 . Geburtstag am 23. Juli noch sein 50Jahr-Jubiläum an der ETH (Eintritt 11.12.1941), oder in der von ihm bevorzugten Zählweise [1] sein 100 . Semester an dieser Hochschule bei insgesamt 135 seit seiner Einschreibung an der Tschechischen Technischen Hochschule in Prag.
Eine Delegation dieser Hochschule (jetzt Universität für Chemie und Technologie) unter der Leitung des Rektors, Prof. C. Cerny war aus Prag angereist, um $V$. Prelog die Ehrendoktorwürde seiner alten Alma Mater zu verleihen. In seiner Ansprache erinnerte Prof. Černy an die historisch-politischen Umstände, die dafür verantwortlich sind, dass der berühmteste Absolvent dieser Hochschule erst so spät von ihr ausgezeichnet werden kann. Die Überreichung von Urkunde und Kette als Symbol der neuen Würde fand dann in der Prof. Prelog noch immer wohlvertrauten tschechischen Sprache statt.

Im Anschluss an diese Zeremonie hielt der Rektor der ETH Zürich, Prof. H. von Gunten, die Laudatio auf den diesjährigen Träger der Prelog-Medaille, Prof. Clayton $\mathrm{H}$. Heathcock von der University of

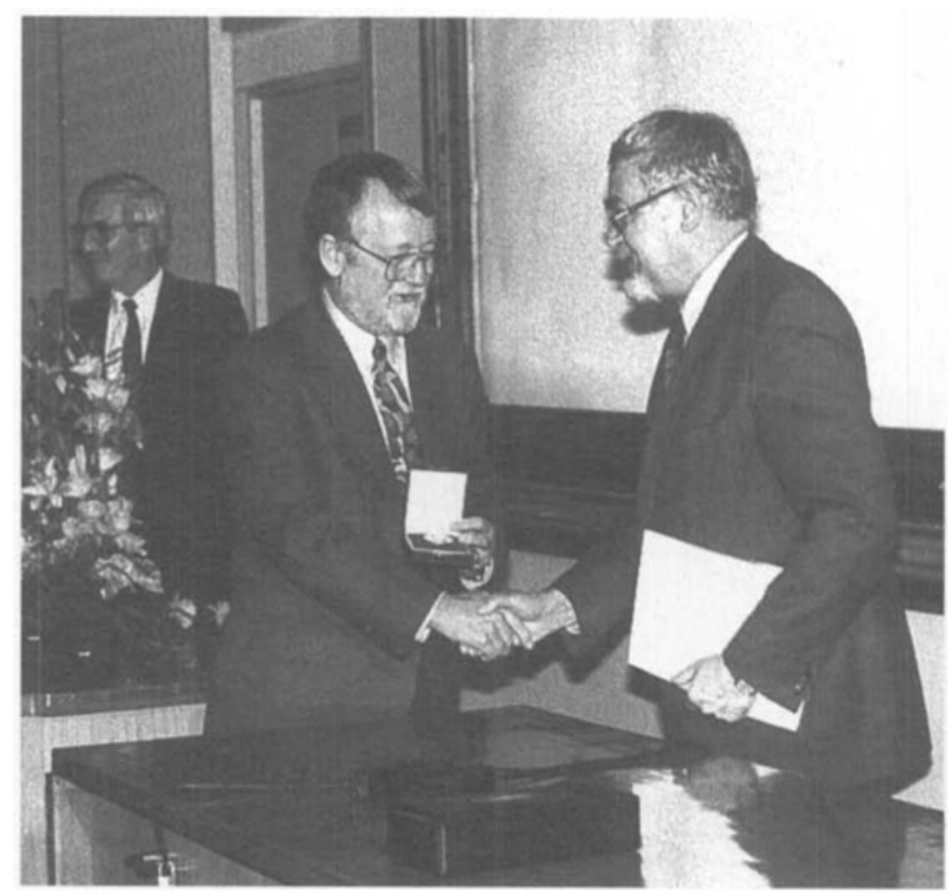

D. Seebach, C.H. Heathcock und H. von Gunten

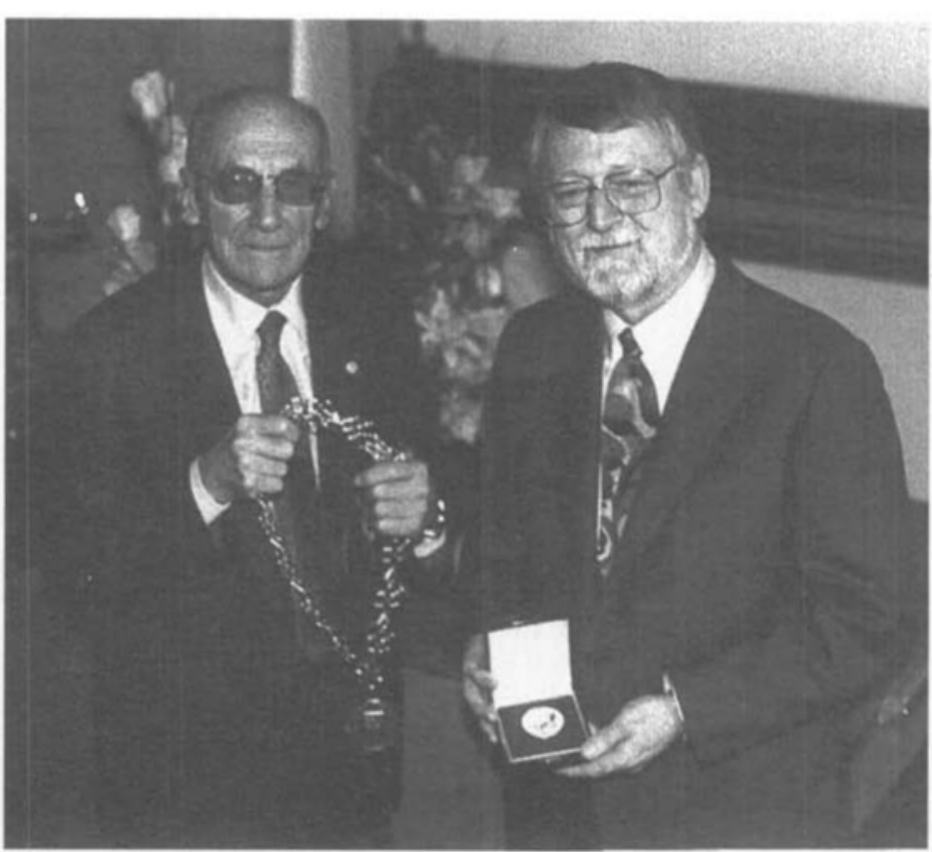

V. Prelog und C.H. Heathcock

California, Berkeley, Als Professor für Bauingenieurwesen liess sich der Rektor die Gelegenheit nicht entgehen, eine Brücke von dieser Veranstaltung zur 700-Jahr-Feier der Eidgenossenschaft und zur kürzlichen Auszeichnung von Prof. R. Ernst mit dem Nobelpreis für Chemie zu schlagen. Erverlieh seiner Hoffnung Ausdruck, dass der - in diesem Jahr positive - Trend bei der Zahl der Chemie-Studenten im Hinblick auf den einheimischen Nachwuchs für die chemische Industrie erhalten bleibt, wobei er, sicherlich zur Genugtuung aller anwesenden Mitglieder der Abteilung für Chemie der ETH festhielt, dass die Bedeutung dieser Abteilung von der Schulleitung nicht an der Zahl der Studierenden gemessen wird; Chemie sei an der ETH kein 'Abbaugebiet'. Prof. von Gunten dankte auch der schweizerischen chemischen Industrie für die essentielle finanzielle Unterstützung der Prelog-Vorlesung.

Die wissenschaftliche Laufbahn des auf Vorschlag des Laboratoriums für Organische Chemie ausgezeichneten Prelog-Preisträgers war den Anwesenden schon durch einen von Prof.A. Eschenmoser verfassten und in der Einladung abgedruckten 


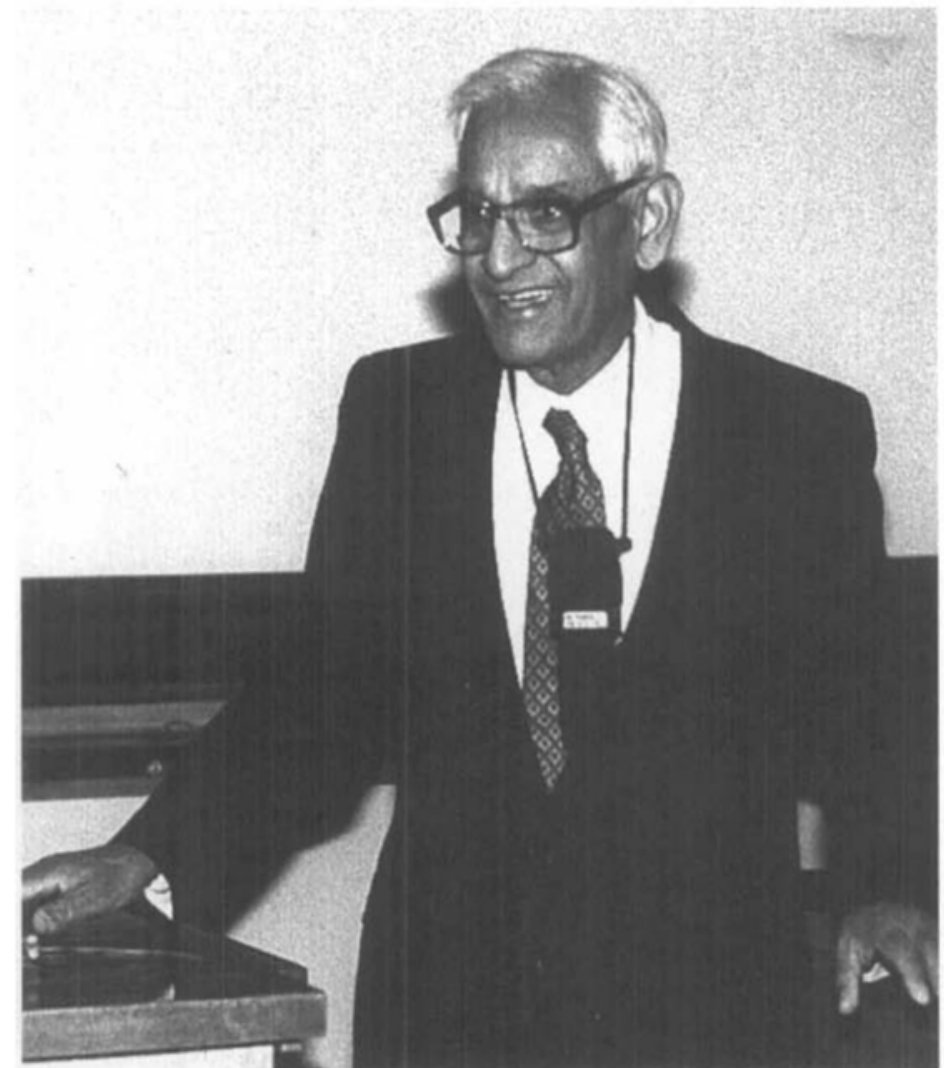

H.G. Khorana
Text bekannt (s. Kasten), aus dem er in seiner Einführung die wesentlichsten Punkte hervorhob. Prof. Heathcock empfing dann die Medaille aus der Hand von Prof. Prelog und hielt die Prelog-Vorlesung zum Thema 'The Fascinating Alkaloids of Yuzuriha: Synthesis and Possible Biosynthesis'.

Nach der Pause würdigte Vizepräsident Prof. $R$. Hütter, der als Mitglied der Schulleitung den verhinderten Präsidenten derETH, Prof. $J$. Nüesch, vertrat, die menschliche Seite von Prof. Prelog, den er durch herausragende Fähigkeiten als Chemiker und Organisator und seine Eigenschaften Gedächtnis und Persönlichkeit charakterisierte. Er wünschte ihm alles Gute für die Zukunft, vor allem Gesundheit und Humor.

Als Geburtstagsgeschenk der Schule konnte Prof. D. Seebach darauf den Vortrag von Prof. H.G. Khorana, eines Lieblingsschülers dès Jubilars, ankündigen. In seiner Einführung skizzierte Prof. D. Arigoni die bewegte wissenschaftliche und persönliche Laufbahn von Prof. Khorana mit der Verleihung des
Nobelpreises 1968 als einem der Höhepunkte. Der Vortrag von Prof. Khorana mit dem Titel 'Lighttransduction by Two Biological Systems: Bacteriorhodopsin and Rhodopsin' schloss beziehungsreich mit zwei Bildern aus der Zeit seines Zürcher Aufenthalts 1948, die den jungen Prof. Prelog und seine damalige Arbeitsgruppe zeigten.

In seinem Schlusswort dankte Prof. D. Seebach der Sekretärin des Laboratoriums, Frau $J$. Bovet, für ihre zum wiederholten Male gelungene Organisation der Prelog-Vorlesung und dieses Festkolloquiums.

\section{A.K. Beck, C. Leumann, E. Zass}

Fotos: $F$. Kreppelt, Laboratorium für org. Chemie, ETH-Zürich

[1] V. Prelog, 'My 132 semesters of chemistry studies', American Chemical Society, Washington, DC, 1991.
Clayton Howell Heathcock was born in San Antonio(Texas) in 1936. He spent his early years there and received a B.S. degree in chemistry from Abilene Christian College, Abilene (Texas) in 1958. After spending two years as supervisor of Chemical Tests for the Champion Paper and Fibre Company in Pasadena (Texas), he returned to school at the University of Colorado and received the Ph.D. in organic chemistry under Alfred Hassner in 1963. After a year of postdoctoral work with Gilbert Stork at Columbia University, he joined the Chemistry Department of the University of California in Berkeley, where he was promoted to associate professor in 1970 and to full professor in 1975; at present he has the distinguished position of a Miller Research Professor at this department. Over the years he has served as chairman of the chemistry department at Berkeley, of an NIH Medicinal Chemistry study group, of the ACS Organic Chemistry Division and of a Gordon Research Conference on Stereochemistry. He has edited an Organic Synthesis Volume and is at present Editor-in-Chief of the Journal of Organic Chemistry.

In 1971, he spent six months at the organic chemistry laboratory at ETH as an academic guest.

In his research, Heathcock is what one might call a central organic chemist. His scientific work is rooted in the field of natural product chemistry, the problems he attacks and the tools he uses are those of organic synthesis, target- as well as method-oriented. Underlying all his work is a distinct inclination to tackle problems whose solutions contribute to our understanding of chemical reactivity. Heathcock's research achievements are documented in over 200 papers and in a series of important review articles. After his doctoral work under Hassner, with whom he had an exceptionally fruitful and productive collaboration on the chemistry of aziridines, he started independent research at Berkeley by working on natural product syntheses in the terpene field; he announced himself to the international community of organic chemists in 1966 with the first total synthesis of the complex tricyclic sesquiterpene hydrocarbon copaene, an achievement carried out single-handedly and notable for the lucidity of the synthesis strategy. Over the years, Heathcock's special flair for the development of strategy as well as methodology has led him to engage in comprehensive research on a wide series of projects in natural product synthesis with target structures varying from sesquiterpenes and pentacyclic triterpenes to compounds of medicinal interest e.g. vernolepin, compactin; quassinoids, and alkaloids. While Heathcock's 1978 synthesis of lycopodine is an important contribution of his earlier research in alkaloid synthesis, his work in this field has culminated recently in brilliant and spectacularly successful syntheses of daphniphyllum alkaloids. Heathcock's work on these complex hexacyclic triterpenoid alkaloids constitutes a fine example of natural product synthesis evolving from a level of 'biophobic' hardcore chemosynthesis into that of selfpropelling biomimetic chemosynthesis, making use of the specific reaction channels through which the biosynthesis is expected to proceed - chemomimetically so to say. This is the level on which an achieved natural product synthesis amounts to a chemical rationalization of the natural product structure.

In the Woodwardian era of natural product synthesis, the dominating strategy for diastereoselection was based on the concept of 'Synthesis via Transient Rings'. During the last 15 years we have witnessed the development of the concepts and methods of 'Acyclic Diastereoselection'. Through them, diastereoselective syntheses of highly complex acyclic or macrocyclic molecules containing multiple stereogenic centers have become feasible. These developments - brought about by the contributions of various research groups - represent a great step forward in the strategy and methodology of chemical synthesis and in our understanding of stereocontrol. Clayton Heathcock has been the pioneer of this development in the field of natural product synthesis. Starting with his first paper 'Stereoselection in the Aldol Condensation' in 1977, about 50 papers on 'Acyclic Stereoselection' have come out of his laboratory; as a whole, they constitute a comprehensive contribution to our knowledge of stereocontrol of reactivity.

Within the last five years, Heathcock has won the Ernest Guenther Award, the Award for Creative Work in Synthetic Organic Chemistry and the A.C. Cope Scholar Award, all from the American Chemical Society. This year - besides receiving the Prelog Medal - he has been elected a member of the prestigious American Academy of Arts and Sciences.

Let us not forget: Heathcock is also a distinguished teacher. Together with his colleague Andrew Streitwieser he has written a most successful textbook 'Introduction to Organic Chemistry'; this book has helped many of our students here at ETH to enjoy and to understand our science. 


\section{Zum siebzigsten Geburtstag von Dr. Jakob Schreiber}

\section{Lieber Schaggi,}

Zwar weiss ich, Du hast es nicht sogerne, wenn man von Deiner Person und Deinen Angelegenheiten besonderes Aufheben macht. Doch mein Brief zum Anlass Deines siebzigsten Geburtstagis bedarf sozusagen eines öffentlichen Forums, denn er entspricht - ich bin ganz sicher auch der Intention so vieler ehemaliger Doktoranden unserer Arbeitsgruppe, denen Du aus ihrer Zeit an der ETH unvergessen bist, und die ebenso wie ich zu Deinem besonderen Geburtstag das Bedürfnis empfinden, Gedanken und Gefühlen der Dankbarkeit und der freundschaftlichen Verbundenheit Ausdruck zu verleihen. Und auch die andern, die mit Dir beruflich zu tun haben oder zu tun hatten, Dich persönlich schätzen und gut mögen, sie alle werden sich freuen, Dich bei dieser Gelegenheit mal ein wenig aufs Podest gehoben zu sehen, und sie werden in die guten Wünsche einstimmen, die wir allesamt mit herzlicher Sympathie zu Deinem Geburtstag Dir mitgeben möchten.

Wenn auch nun schon seit fünf Jahren pensioniert, bist Du noch fast täglich im Laboratorium anzutreffen - auch bei Dir könnte man sagen: 'emeritiert aber nicht eremitiert' - und Du bist nach wie vor mit dabei, wenn es um HPLC-Probleme oder sonstige Sorgen des Laboratoriumalltags geht. So ist es halt seit jeher gewesen, Du bist von dieser
Arbeitsgruppe 'einfach nicht wegzudenken'. Seit Jahrzehnten sorgst Du in ihr (zusammen mit Dorothee Felix, Hermie und Engelbert Zass) für etwas sehr Kostbares, für die Kontinuität. Alles was in dieser Gruppe, seit sie existiert (Du warst ihr erster Doktorand), an wissenschaftlicher Forschung gelaufen ist, trägt auch Deinen Stempel; die Danksagungen an Dich in den Dissertationen unserer Doktoranden bezeugen es. Generationen von Doktoranden und Postdoktoranden bist Du mit Rat und Tat beigestanden. Du konntest dies wegen der natürlichen Autorität Deiner Persönlichkeit und vor allem auch kraft Deines ganz und gar ausserordentlichen Experimentiertalents und praktischen Sinns, Deiner erstaunlichen Fähigkeit, in schwierigen experimentellen Problemsituationen, welcher Art Sie auch immer seien, überzeugende, oft genial einfache, d.h. wie wir eben sagen - typisch Schreiber'sche Lösungen zu erkennen. Da gibt es Beispiele auf verschiedenartigsten Gebieten; sie reichen von Schreiber'schen Reaktions-, Destillations- und Chromatographier-Apparaturen, Schreiber schen Forschungslabor- und Praktikumslabor-Einrichtungen bis zu den vom Institut und den Bauleuten de ETH übernommenen Schreiber schen Plänen für den Bau chemischer Hochschullaboratorien. Auch Dinge wie z.B. die metallenen Rahmen der in unserem Laborgang hängen-

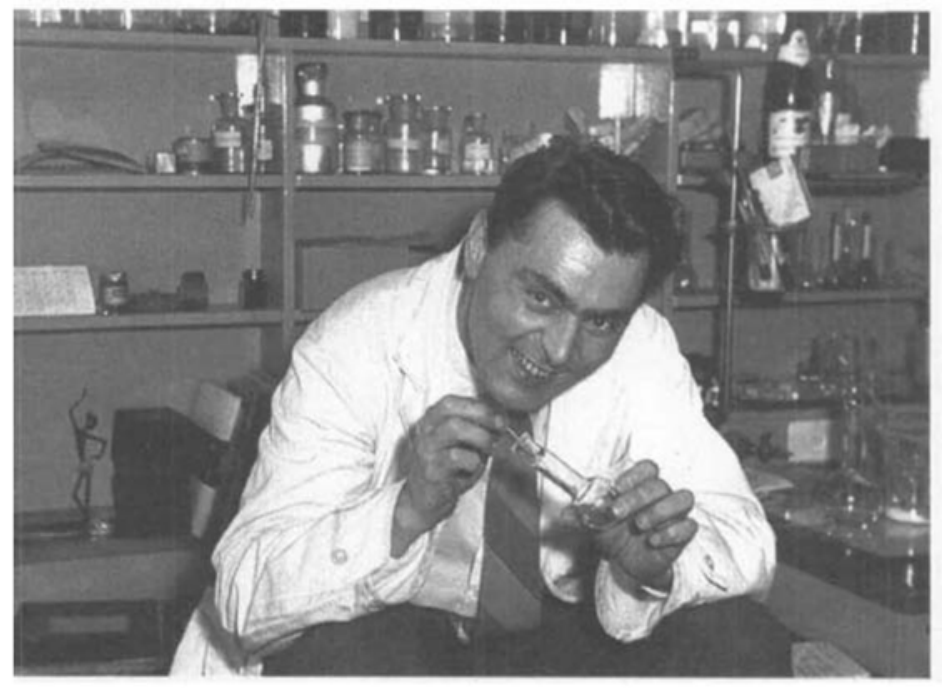

den Bilder stammen von Dir, oder der Corphin-Grill, der in Dorothee's GC-Labor hängt; ja es gab mal eine Zeit, da warst Du recht eigentlich künstlerisch tätig, da schmückten bestechende Hervorbringungen aus Deiner Hand (z.B. Nagelreliefs) die Wände.

Mit Dir zusammen Forschung zu betreiben war wunderbar. Dies wegen Deiner Kreativität und Deine beispiellosen Effizienz, Deine Freude am Experimentieren, Deine Begeisterungsfähigkeit, der Unbedingtheit und Kraft, womit Du Probleme angingst. Wie Vieles wäre doch wohl kaum je zustande gekommen, hättest es nicht Du in den Händen gehabt. Dies hatte schon mit Deiner Diplomarbeit 'Über die Konstitution der Caryophyllensäure' begonnen, in welcher Du inner den zu Verfügung stehenden vier Wochen durch einen Einsatz sondergleichen die Entscheidung zwischen zwei Alternativstrukturen herbeiführtest und dadurch einen wichtigen Beitrag zur Festigung der

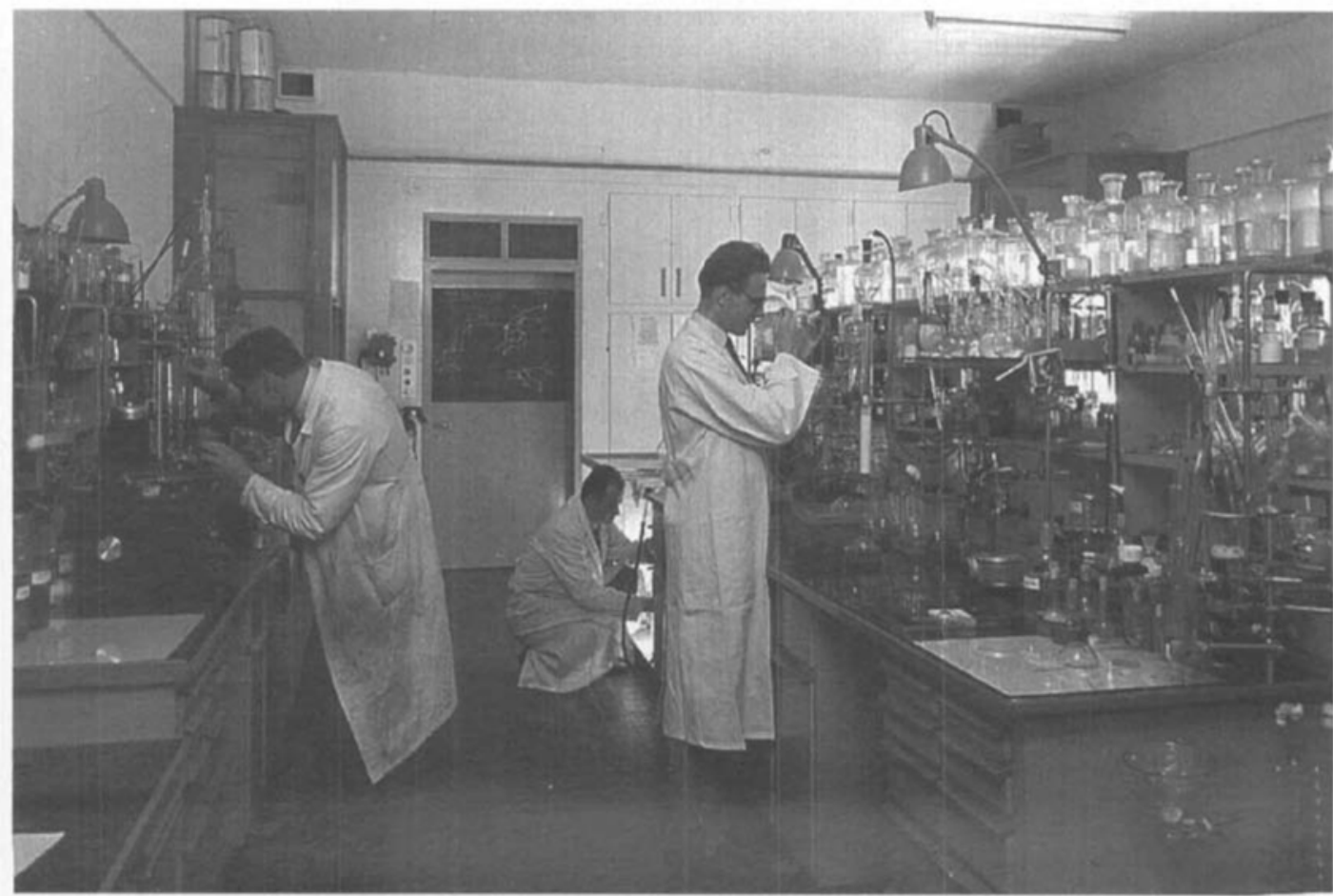

damals neu aufgekommenen Anschauungen über die Konstitution des Sesquiterpens $\beta$-Caryophyllen leistetest (WS 1950). Oder wie Du dann kurz darauf jenen sechswöchigen Spurt im Laboratorium hinlegtest, in welchem es um den Konstitutionsbeweis für den Sesquiterpenalkohol Lanceol durch Synthese eines seiner Abbauprodukte ging (1951)! In Deiner Promotionsarbeit (1953) hast Du eine achtstufige Totalsynthese eines D. Homosteroids ausgehend von 1Methylcyclohexan-2,6-dion durchgeführt; die Reaktionsfolge birgt das erste Beispiel einer reduktiven $\alpha$ Alkylierung eines $\alpha, \beta$-ungesättigten Enonsystems, ein Reaktionskonzept, das später von andern aufgegriffen und weiter entwickelt wurde und schliesslich in das heute so bedeutungsvolle Synthesekonzept der Konzertierung von nukleophilen $\beta$-Additionen mit elektrophilen $\alpha$-Substitutionen bei $\alpha, \beta$ ungesättigten Carbonylsystemen einmündete. Auf einen Höhepunkt Deiner chemischen Frühzeit gelangtest Du mit Deiner damals berühmten kolorimetrischen Bestimmungsmethode der relativen $\mathrm{Ge}$ schwindigkeit der Oxidation sekundärer alicyclischer Alkohole mit Chromsäure (1955). Es wardie (noch NMR-lose) Zeit, da Dir Chemiker aus Laboratorien in aller Welt Proben solcher Alkohole zusandten, weil Deine Messung die Methode der Wahl für deren Konfigurationsbestimmung war. Dann aber kamen die heroischen Jahre des Colchicins. Auch hier warst Du der Hauptakteur, und für immer wird Dein Name mit der ersten chemischen Synthese dieses exquisiten Alkaloidmoleküls (1959) verbunden bleiben

Nebenprodukte des ColchicinProjekts waren Deine Arbeit über eine Synthese des Troponsystems, die von einem speziellen Reaktionsprinzip Gebrauch machte, das man heute als Beispiel einer 'Umpolung' betrachten würde (1958), sowie die Untersuchung über die konstitutionelle S.2-Selektivität der katalytischen Spaltung von Carbonsäuree- 


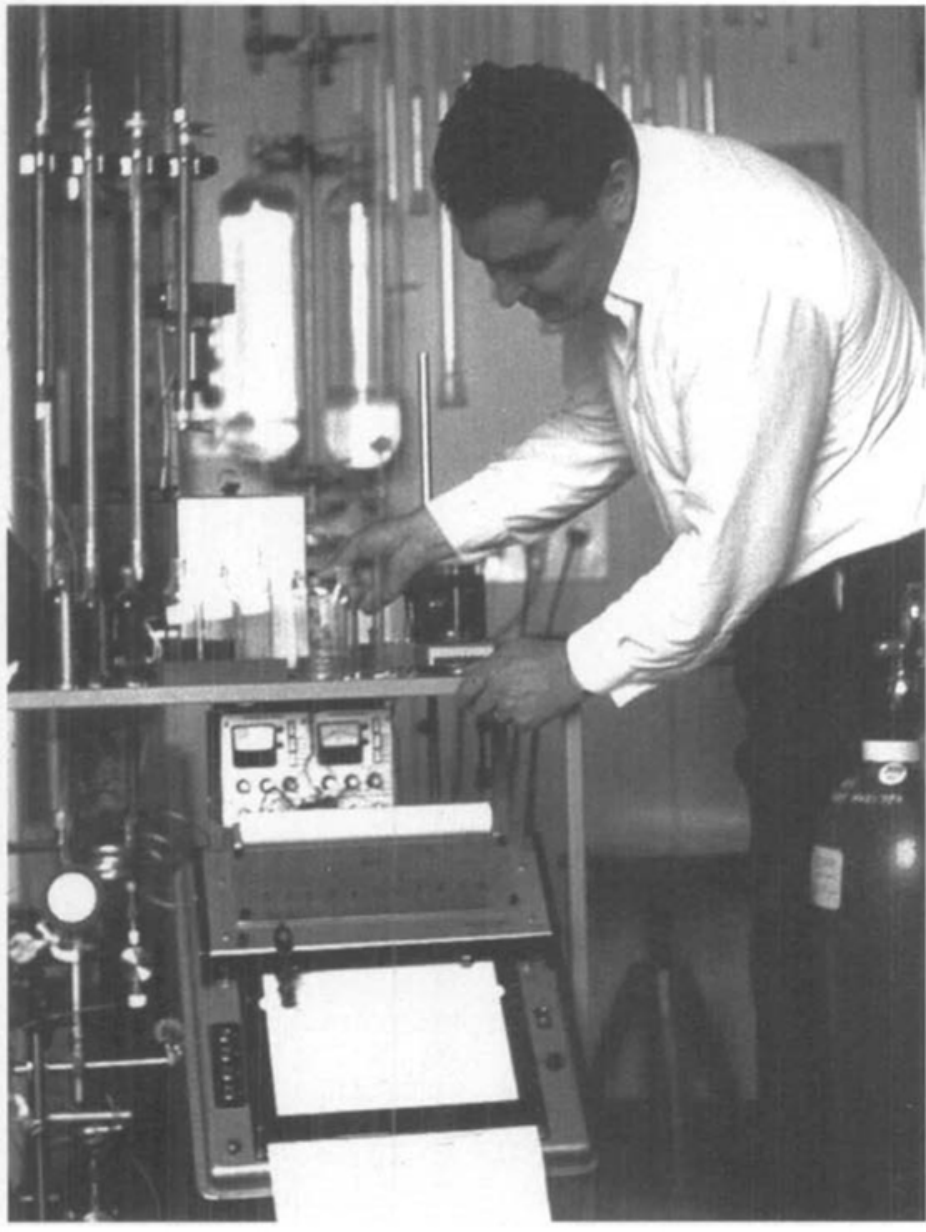

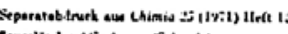

Ein Beispie/ zur Anwendung der schnellen Flüssigchromatographie in der organischen Synthese *

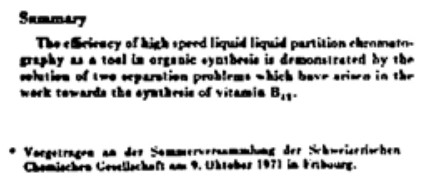

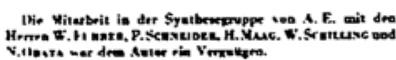
J.scontissn

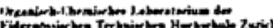

stern mit Lithiumjodid (1959). Bald darauf begann die Zeit der Faszination durch die Peptidchemie, und mit ihr Dein Aufenthalt in den USA, wo Du am NIH sozusagen für ein Jahr 'fremd gingst' (1962/63). Nach Deiner Rückkehr entstand in unserem Laboratorium der Schreiber' sche Aminosäure-Analysator, eine Maschine von Dir mit eigener Hand gebaut, die Du Deinen Cadillac nanntest. An ihr hast Du Dein Konstruktionstalent und Deine Konstruktionslust so richtig ausgelebt; aber was Du dabei für Dich entdecktest, war ein besonderes Flair für die Chromatographie, ihre Technik und ihre apparative Fortentwicklung. Von da an hast Du Dich zum grossen Glück für unsere Arbeitsgruppe - eigenständig mit der Chromatographie beschäftigt. Nicht dass Du gleich aufgehört hättest, präparative Chemie zu betreiben - Deine Übertragung der Methode der Veresterung von Carbonsäuren mit benzylischen Alkoholen durch DMF-dienopentylacetal auf die Fixierung von Aminosäuren an Hydroxymethyl-polystyrol (1965), oder Deine Handschrift in den Durchführungsvorschriften der $\alpha, \beta$-Epoxyketon $\rightarrow$ Alkinon-Fragmentierung (1967) oder der Herstellung des $N, N$-Dimethyl- $N$-methyliden-ammonium-jodids (1970) belegen dies-doch zu jener Zeit der grossen Kletterpartien im Gebirge der Modellcorrine und am Hauptmassiv $B_{12}$, da bliebst Du vorerst so etwas wie ein wohlwollender Beobachter, der mal schauen wollte, wie weit sie wohl kommen werden ohne ihn, der aber doch wie ein erfahrener und loyaler Bergführer darauf vorbereitet war, zu Hilfe zu eilen, falls Absturzgefahr aufkommen sollte. die ETH-Gruppe, als auch jene an der Harvard mit dem Problem konfrontiert wurde, die nach erfolgrei$\operatorname{cher}(\mathrm{A} \rightarrow \mathrm{D})$ - bzw. $(\mathrm{A} \rightarrow \mathrm{B})$-Secocorrin $\rightarrow$ Corrincyclisierung anfallenden komplexen Gemische diastereoisomerer 5,10-Bisnor-cobyrinsäurederivate chromatograUnd beileibe, die kam. Als sowohl

\section{SCHWEIZERISCHF CHEMISCHE GESELLSCHAFT SOCIETÉ SUISSE DE CHIMIE}

DER VORSTAND DER

SCHWEIZERISCHEN CHBMISCHBN GESBLLSCHATT HAT DEN

\section{PREIS DER SCHWEIZERISCHEN CHEMISCHEN GESELLSCHAFT} MTT WRRNER-MEDNLIF

HERRN DR. JAKOB SCHREIBER, OBERASSISTBNT, ZORICA

$$
\text { PUR }
$$

SELNE VE DIBNSTE

AUF DEM GEBIETE DER ORGANISCHEN SYNTHBSB

VERLJEHEN

ZURICH, DEN 2T, APRIL 1972

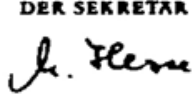

DER PKXSIDENT

$$
\text { fl. } \left.\int_{i}, \ldots\right)^{-}
$$

phisch zu trennen, da war Deine Zeit gekommen. Aus eigener Initiative und mit ausgesprochenem Weitblick hattest Du nämlich gerade ungefähr ein Jahr zuvor damit begonnen gehabt, Dich mit der damals in der analytisch-chemischen Literatur aufkommenden 'High Performance LiquidChromatography' theoretisch und apparativ vertraut zu machen. Du hattest Dir eine HPLC-Apparatur selbst gebaut, und mit ihr gelang $\mathrm{Dir}$ dann nicht nur die Lösung des erwähnten, für den erfolgreichen $\mathrm{Ab}$ schluss der Vitamin $B_{12}$-Synthesen vitalen Trennproblems, sondern es war dies der erste Einsatz der HPLChromatographie auf dem Gebiete derorganischen Synthese überhaupt. Nicht nur die ETH-, sondern ebensosehr auch die Harvard-Gruppe haben damals von Deiner Pionierleistung gewaltig gezehrt; die kurz darauf in den USA vehement einsetzende HPLC-Propaganda einer US-Firma lief dann allerdings mit Bezug auf nicht Deinen, sondern einen viel bekannteren und damit geschäftlich wirksameren Namen. Doch die Schweizerische Chemische Gesellschaft hat damals Deine wissenschaftliche Leistung sowie Deine früheren Beiträge zur synthetischen Chemie öffentlich gewürdigt; sie hat Dir 1974 den Preis der Gesellschaft mit der Werner-Medaille verliehen.

In jener Pionierzeit der HPLChromatographie haben verschiedene Chemie-Institute des In- und Auslandes Dich eingeladen, ihnen durch Vorträge und praktische $\mathrm{Be}$ ratung bei der Einführung der neuen Chromatographietechnik behilflich $\mathrm{zu}$ sein. Und unsere eigene Gruppe hat natürlich seither das Privileg genossen, durch Dich auf diesem unaufhaltsam wichtiger gewordenen Gebiete der HPLC-Technik fit zu bleiben. Ungezählte Doktoranden aus der eigenen Gruppe und auch aus Nachbargruppen haben über die Jahre hinweg von Deiner Kompetenz, Deiner tatkräftigen und kreativen Hilfe profitiert. Man kann diesen sozusagen 'delokalisierten' Beitrag, den Du damit zur Forschung unserer Gruppe und unseres Instituts geleistet hast, wohl gar nicht hoch genug einschätzen.

Aussergewöhnlich ist - nebst Deinem Beitrag zur chemischen Forschung - noch so vieles Andere an Dir. So habe ich wohl kaum je einen anderen ETH-Angehörigen gekannt, der ein glühenderer ETHPatriot gewesen wäre, als Du einer bist. Mit Deiner Identifikation mit dieser Schule, Deiner Loyalität zu ihr, Deiner Sorge um sie, könntest Du Etlichen ein Vorbild gewesen sein. Die gleiche Art von Unbedingtheit prägt auch Deine Einstellung zu Deinem Beruf als Chemiker und zur Chemie als Wissenschaft. Und so bedeutet es denn für Dich mit Recht eine ganz besondere Freude, dass Dein ältester Sohn zur Zeit an dieser Schule ein Chemiestudium absolviert. Dein Wochenend- und Ferienhaus in den Bündner Bergen, dessen Bau Du noch im 

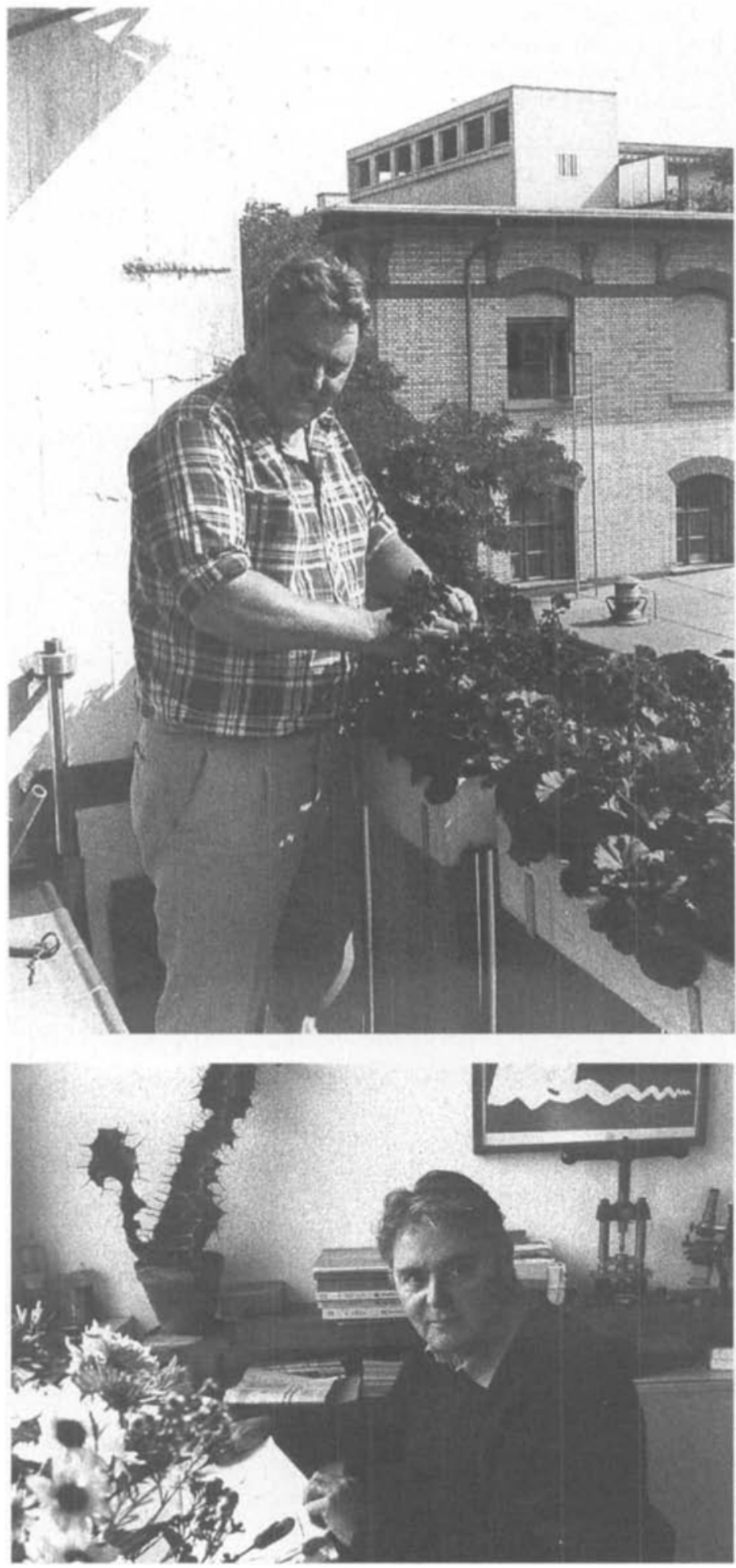

Alter von mehr als 60 Jahren wagtest, hast Du 'Tgiesa Corphin' getauft. Natürlich hast Du die Struktur dieses Hauses selbst geplant, und dessen gesamter Innenausbau stammt auch aus Deiner Hand. Überhaupt, das Planen und Einrichten von Häusern ist eine Deiner Leidenschaften. Du hast, soweit ich orientiert bin, nicht weniger als deren drei eingerichtet. An der ETH sind es die organisch-chemischen Forschungs- und Praktikumslaboratorien des letzten Neubaus, deren Planung weitgehend von Dir stammt; solch ein innenarchitektonischer Beitrag stand nicht in Deinem Pflichtenheft als Oberassistent, er ist denn auch seinerzeit von der ETH offiziell anerkannt und gewürdoch kraft der Vielfalt Deiner Ta-

Albert Eschenmoser
Schweizerische Gesellschaft der Arbeitshygieniker (SGAH)

Société Suisse des Hygienistes du Travail (SSHT)

\section{Arbeitshygiene in der Schweiz: Stellenwert und} fachtechnische Aspekte

Über dieses Thema wird am Mittwoch, 22. Januar 1992 im ETHZentrum Zürich (HauptgebäudeAuditorium maximum) von der Schweizerischen Gesellschaft de Arbeitshygieniker, zusammen mit dem Institut für Toxikologie der ETH und Universität Zürich (Prof. Dr. Ch. Schlatter) und dem Institut fü Hygiene und Arbeitsphysiologie der ETH Zürich (Prof. Dr. H. Krueger) eine Vortragstagung organisier (9.30-ca. 17.30 h; keine Anmeldung erforderlich; Eintritt frei)

Sicherheit am Arbeitsplatz beinhaltet nicht nur den Schutz vor Unfällen. Chemikalien, Lärm und Wärme am Arbeitsplatz können ebenfalls gesundheitliche Auswirkungen haben. Diese äussern sich meist nicht unmittelbar. In der Regel werden sie erst nach längere Expositionszeit wirksam, sind dann aber oft nicht mehr heilbar. Erkennung und Vorbeugung ist darum von grösster Bedeutung.

Die Methoden zur Bestimmung der Exposition des Arbeitnehmers gegenüber Chemikalien und physikalischen Einflüssen sind meist kompliziert und aufwendig. Die Beurteilung möglicher Gesundheitsschädigungen basiert in der Regel auf toxikologischen Untersu-

chungen an Tieren. Sorgfältige Beobachtungen von Befunden am Menschen in Zusammenhang mit den entsprechenden Expositionsdaten ergeben weitere wichtige Unterlagen. Mit diesen arbeitshygienischen Aktivitäten sollen die Arbeitnehmer vor bekannten Schadenfaktoren geschützt werden, und es sollen auch neue potentielle Gefährdungen so früh erkannt werden, dass überhaupt keine Schädigungen beim Menschen vorkommen.

Durch diese Vortragstagung soll den Teilnehmern das Fachgebiet der Arbeitshygiene näher gebracht werden. In den Berichten über die diesbezüglichen Aktivitäten aus Hochschulen, Industrie und Behörden werden Erreichtes dargestellt und Lücken aufgezeigt.

Die Veranstaltung fügt sich in das Konzept der EG ein, welche das Jahr 1992 zum Europäischen Jahr für Sicherheit, Arbeitshygiene und Gesundheitsschutz am Arbeitsplatz. erklärt hat.

A.Steinegger, $\mathrm{CH}-3973$ Venthone

Ch. Schlatter

Institut für Toxikologie der ETH und Universität Zürich

$\mathrm{CH}-8603$ Schwerzenbach

\section{European Federation for Medicinal Chemistry and the American Chemical Society, Division of Medicinal Chemistry}

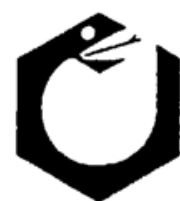

digt worden. Wie leicht hättest Du lente auch ein hervorragender Architekt oder ein erfolgreicher Designer werden können. Dass Du organischer Chemiker geworden bist, ist unser aller, die mit Dir als Chemiker zu tun bekamen, gutes Geschick, natürlich ganz besonders auch das meinige. Angesichts unserer nunmehr sage und schreibe 40jährigen Zusammenarbeit drängt es mich, Dir zu Deinem siebzigsten Geburtstag ein Wort des persönlichen Dankes zu sagen, für das, was Du unserer Gruppe gegeben hast und für eine 40jährige, glückhafte Freundschaft.
The Section of Medicinal Chemistry of the Swiss Chemical Society cordially invites you to attend the

\section{XIIth International Symposium on Medicinal Chemistry}

Basel, Switzerland, September 13-17,1992

\section{Background}

The European Federation for Medicinal Chemistry, comprised of representatives of national medicinal chemistry organizations in Europe, organizes biennial International Medicinal Chemistry Symposia. Previous symposia were held in Florence (1962), Münster (1968), Milan (1972), Noordwijkerhout (1974), Paris (1976), Brighton (1978), Torremolinos (1980), Toronto (1982, in cooperation with the Medicinal Chemistry Divisions of the Chemical Institute of Canada and the American Chemical Society), Uppsala (1984), Berlin/West (1986), Budapest (1988), and Jerusalem (1990).

\section{Duration of Conference}

The Symposium will be held in Basel at the European World Trade and Convention Center, starting on Sunday afternoon (September 13) with the Registration and Inaugural Lecture. The scientific programme will take 

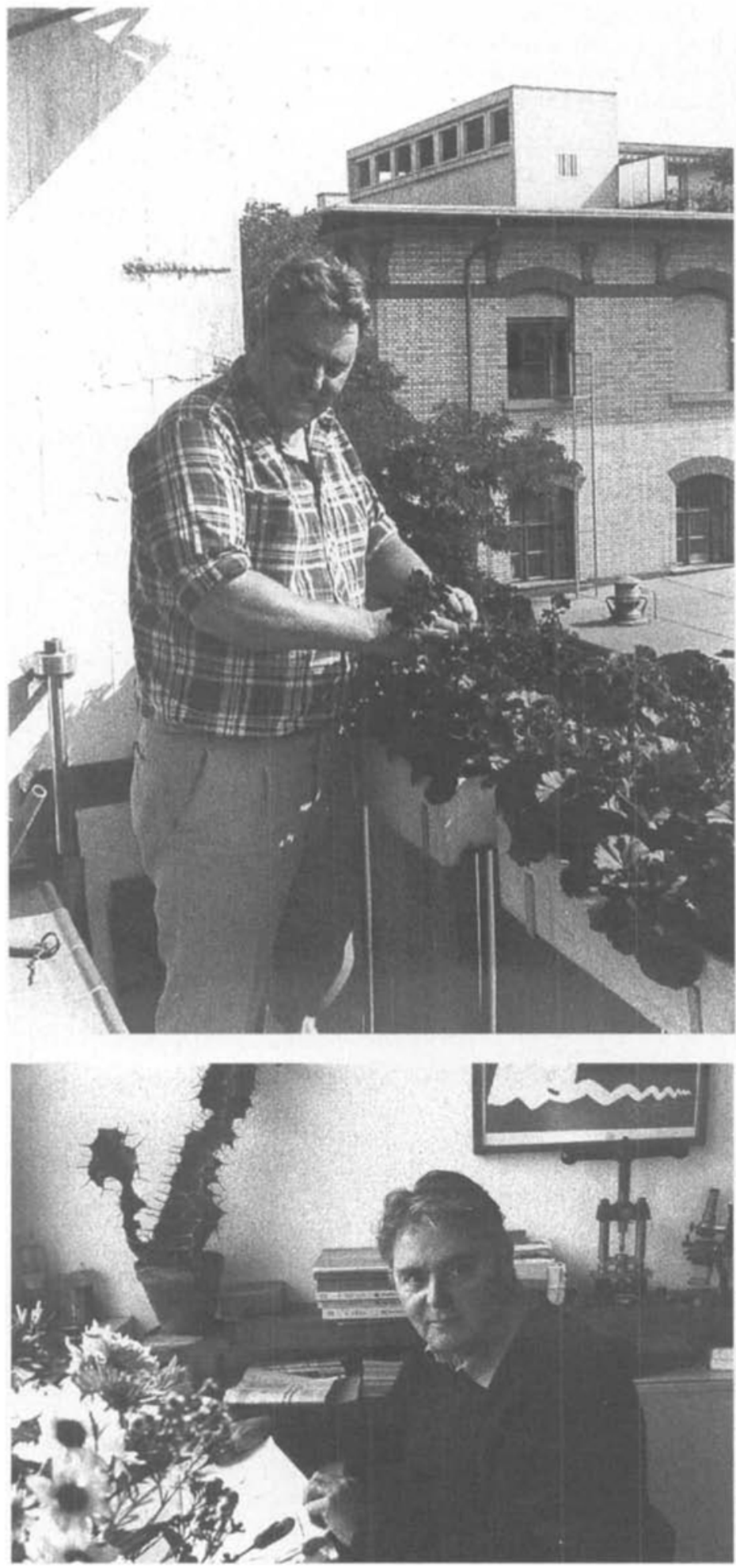

Alter von mehr als 60 Jahren wagtest, hast Du 'Tgiesa Corphin' getauft. Natürlich hast Du die Struktur dieses Hauses selbst geplant, und dessen gesamter Innenausbau stammt auch aus Deiner Hand. Überhaupt, das Planen und Einrichten von Häusern ist eine Deiner Leidenschaften. Du hast, soweit ich orientiert bin, nicht weniger als deren drei eingerichtet. An der ETH sind es die organisch-chemischen Forschungs- und Praktikumslaboratorien des letzten Neubaus, deren Planung weitgehend von Dir stammt; solch ein innenarchitektonischer Beitrag stand nicht in Deinem Pflichtenheft als Oberassistent, er ist denn auch seinerzeit von der ETH offiziell anerkannt und gewürdoch kraft der Vielfalt Deiner Ta-

Albert Eschenmoser
Schweizerische Gesellschaft der Arbeitshygieniker (SGAH)

Société Suisse des Hygienistes du Travail (SSHT)

\section{Arbeitshygiene in der Schweiz: Stellenwert und} fachtechnische Aspekte

Über dieses Thema wird am Mittwoch, 22. Januar 1992 im ETHZentrum Zürich (HauptgebäudeAuditorium maximum) von der Schweizerischen Gesellschaft de Arbeitshygieniker, zusammen mit dem Institut für Toxikologie der ETH und Universität Zürich (Prof. Dr. Ch. Schlatter) und dem Institut fü Hygiene und Arbeitsphysiologie der ETH Zürich (Prof. Dr. H. Krueger) eine Vortragstagung organisier (9.30-ca. 17.30 h; keine Anmeldung erforderlich; Eintritt frei)

Sicherheit am Arbeitsplatz beinhaltet nicht nur den Schutz vor Unfällen. Chemikalien, Lärm und Wärme am Arbeitsplatz können ebenfalls gesundheitliche Auswirkungen haben. Diese äussern sich meist nicht unmittelbar. In der Regel werden sie erst nach längere Expositionszeit wirksam, sind dann aber oft nicht mehr heilbar. Erkennung und Vorbeugung ist darum von grösster Bedeutung.

Die Methoden zur Bestimmung der Exposition des Arbeitnehmers gegenüber Chemikalien und physikalischen Einflüssen sind meist kompliziert und aufwendig. Die Beurteilung möglicher Gesundheitsschädigungen basiert in der Regel auf toxikologischen Untersu-

chungen an Tieren. Sorgfältige Beobachtungen von Befunden am Menschen in Zusammenhang mit den entsprechenden Expositionsdaten ergeben weitere wichtige Unterlagen. Mit diesen arbeitshygienischen Aktivitäten sollen die Arbeitnehmer vor bekannten Schadenfaktoren geschützt werden, und es sollen auch neue potentielle Gefährdungen so früh erkannt werden, dass überhaupt keine Schädigungen beim Menschen vorkommen.

Durch diese Vortragstagung soll den Teilnehmern das Fachgebiet der Arbeitshygiene näher gebracht werden. In den Berichten über die diesbezüglichen Aktivitäten aus Hochschulen, Industrie und Behörden werden Erreichtes dargestellt und Lücken aufgezeigt.

Die Veranstaltung fügt sich in das Konzept der EG ein, welche das Jahr 1992 zum Europäischen Jahr für Sicherheit, Arbeitshygiene und Gesundheitsschutz am Arbeitsplatz. erklärt hat.

A.Steinegger, $\mathrm{CH}-3973$ Venthone

Ch. Schlatter

Institut für Toxikologie der ETH und Universität Zürich

$\mathrm{CH}-8603$ Schwerzenbach

\section{European Federation for Medicinal Chemistry and the American Chemical Society, Division of Medicinal Chemistry}

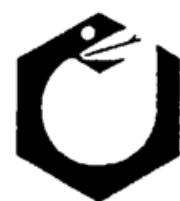

digt worden. Wie leicht hättest Du lente auch ein hervorragender Architekt oder ein erfolgreicher Designer werden können. Dass Du organischer Chemiker geworden bist, ist unser aller, die mit Dir als Chemiker zu tun bekamen, gutes Geschick, natürlich ganz besonders auch das meinige. Angesichts unserer nunmehr sage und schreibe 40jährigen Zusammenarbeit drängt es mich, Dir zu Deinem siebzigsten Geburtstag ein Wort des persönlichen Dankes zu sagen, für das, was Du unserer Gruppe gegeben hast und für eine 40jährige, glückhafte Freundschaft.
The Section of Medicinal Chemistry of the Swiss Chemical Society cordially invites you to attend the

\section{XIIth International Symposium on Medicinal Chemistry}

Basel, Switzerland, September 13-17,1992

\section{Background}

The European Federation for Medicinal Chemistry, comprised of representatives of national medicinal chemistry organizations in Europe, organizes biennial International Medicinal Chemistry Symposia. Previous symposia were held in Florence (1962), Münster (1968), Milan (1972), Noordwijkerhout (1974), Paris (1976), Brighton (1978), Torremolinos (1980), Toronto (1982, in cooperation with the Medicinal Chemistry Divisions of the Chemical Institute of Canada and the American Chemical Society), Uppsala (1984), Berlin/West (1986), Budapest (1988), and Jerusalem (1990).

\section{Duration of Conference}

The Symposium will be held in Basel at the European World Trade and Convention Center, starting on Sunday afternoon (September 13) with the Registration and Inaugural Lecture. The scientific programme will take 

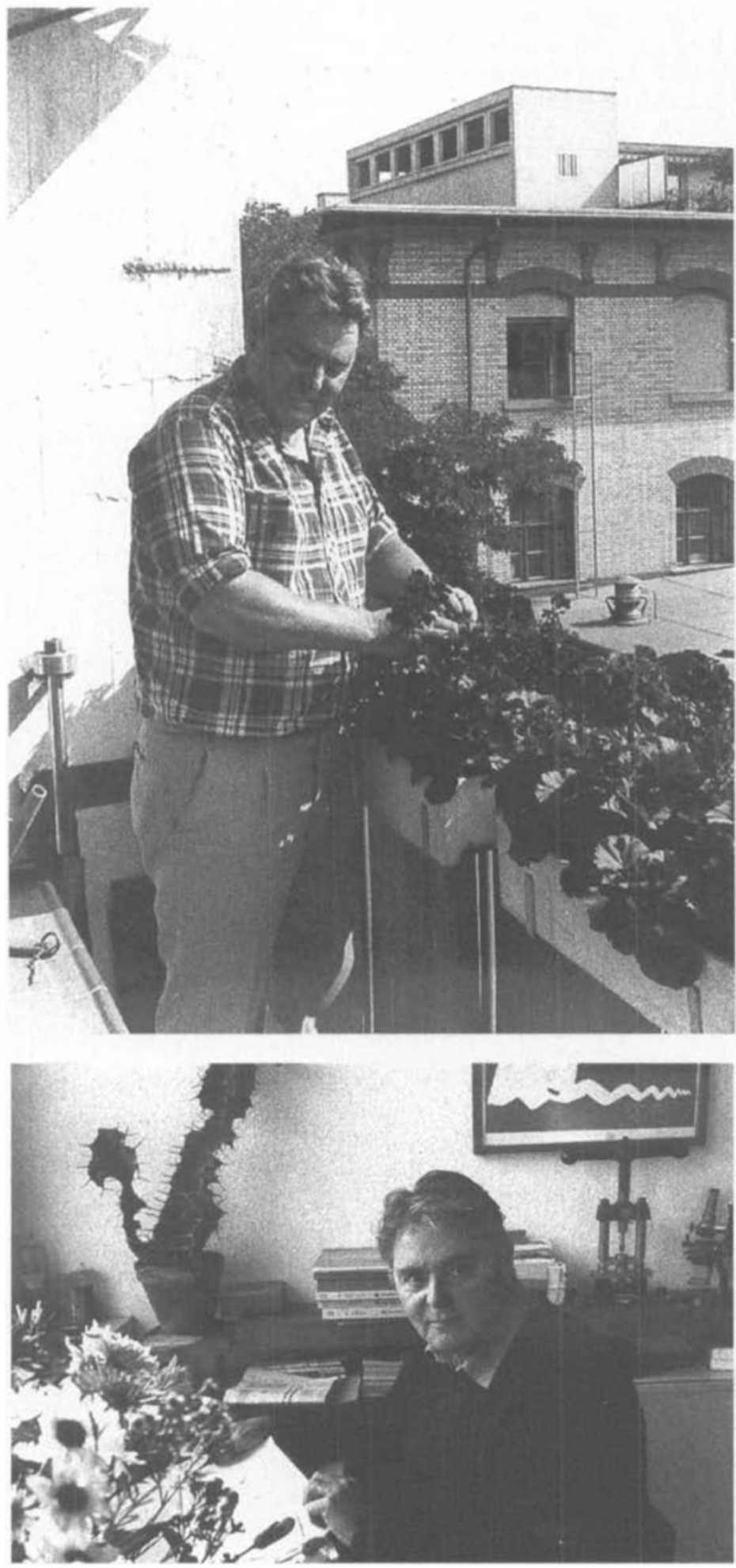

Alter von mehr als 60 Jahren wagtest, hast Du 'Tgiesa Corphin' getauft. Natürlich hast Du die Struktur dieses Hauses selbst geplant, und dessen gesamter Innenausbau stammt auch aus Deiner Hand. Überhaupt, das Planen und Einrichten von Häusern ist eine Deiner Leidenschaften. Du hast, soweit ich orientiert bin, nicht weniger als deren drei eingerichtet. An der ETH sind es die organisch-chemischen Forschungs- und Praktikumslaboratorien des letzten Neubaus, deren Planung weitgehend von Dir stammt; solch ein innenarchitektonischer Beitrag stand nicht in Deinem Pflichtenheft als Oberassistent, er ist denn auch seinerzeit von der ETH offiziell anerkannt und gewürdoch kraft der Vielfalt Deiner Ta-

Albert Eschenmoser
Schweizerische Gesellschaft der Arbeitshygieniker (SGAH)

Société Suisse des Hygienistes du Travail (SSHT)

\section{Arbeitshygiene in der Schweiz: Stellenwert und} fachtechnische Aspekte

Über dieses Thema wird am Mittwoch, 22. Januar 1992 im ETHZentrum Zürich (HauptgebäudeAuditorium maximum) von der Schweizerischen Gesellschaft de Arbeitshygieniker, zusammen mit dem Institut für Toxikologie der ETH und Universität Zürich (Prof. Dr. Ch. Schlatter) und dem Institut fü Hygiene und Arbeitsphysiologie der ETH Zürich (Prof. Dr. H. Krueger) eine Vortragstagung organisier (9.30-ca. 17.30 h; keine Anmeldung erforderlich; Eintritt frei)

Sicherheit am Arbeitsplatz beinhaltet nicht nur den Schutz vor Unfällen. Chemikalien, Lärm und Wärme am Arbeitsplatz können ebenfalls gesundheitliche Auswirkungen haben. Diese äussern sich meist nicht unmittelbar. In der Regel werden sie erst nach längere Expositionszeit wirksam, sind dann aber oft nicht mehr heilbar. Erkennung und Vorbeugung ist darum von grösster Bedeutung.

Die Methoden zur Bestimmung der Exposition des Arbeitnehmers gegenüber Chemikalien und physikalischen Einflüssen sind meist kompliziert und aufwendig. Die Beurteilung möglicher Gesundheitsschädigungen basiert in der Regel auf toxikologischen Untersu-

chungen an Tieren. Sorgfältige Beobachtungen von Befunden am Menschen in Zusammenhang mit den entsprechenden Expositionsdaten ergeben weitere wichtige Unterlagen. Mit diesen arbeitshygienischen Aktivitäten sollen die Arbeitnehmer vor bekannten Schadenfaktoren geschützt werden, und es sollen auch neue potentielle Gefährdungen so früh erkannt werden, dass überhaupt keine Schädigungen beim Menschen vorkommen.

Durch diese Vortragstagung soll den Teilnehmern das Fachgebiet der Arbeitshygiene näher gebracht werden. In den Berichten über die diesbezüglichen Aktivitäten aus Hochschulen, Industrie und Behörden werden Erreichtes dargestellt und Lücken aufgezeigt.

Die Veranstaltung fügt sich in das Konzept der EG ein, welche das Jahr 1992 zum Europäischen Jahr für Sicherheit, Arbeitshygiene und Gesundheitsschutz am Arbeitsplatz. erklärt hat.

A.Steinegger, $\mathrm{CH}-3973$ Venthone

Ch. Schlatter

Institut für Toxikologie der ETH und Universität Zürich

$\mathrm{CH}-8603$ Schwerzenbach

\section{European Federation for Medicinal Chemistry and the American Chemical Society, Division of Medicinal Chemistry}

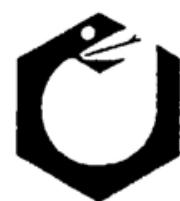

digt worden. Wie leicht hättest Du lente auch ein hervorragender Architekt oder ein erfolgreicher Designer werden können. Dass Du organischer Chemiker geworden bist, ist unser aller, die mit Dir als Chemiker zu tun bekamen, gutes Geschick, natürlich ganz besonders auch das meinige. Angesichts unserer nunmehr sage und schreibe 40jährigen Zusammenarbeit drängt es mich, Dir zu Deinem siebzigsten Geburtstag ein Wort des persönlichen Dankes zu sagen, für das, was Du unserer Gruppe gegeben hast und für eine 40jährige, glückhafte Freundschaft.
The Section of Medicinal Chemistry of the Swiss Chemical Society cordially invites you to attend the

\section{XIIth International Symposium on Medicinal Chemistry}

Basel, Switzerland, September 13-17,1992

\section{Background}

The European Federation for Medicinal Chemistry, comprised of representatives of national medicinal chemistry organizations in Europe, organizes biennial International Medicinal Chemistry Symposia. Previous symposia were held in Florence (1962), Münster (1968), Milan (1972), Noordwijkerhout (1974), Paris (1976), Brighton (1978), Torremolinos (1980), Toronto (1982, in cooperation with the Medicinal Chemistry Divisions of the Chemical Institute of Canada and the American Chemical Society), Uppsala (1984), Berlin/West (1986), Budapest (1988), and Jerusalem (1990).

\section{Duration of Conference}

The Symposium will be held in Basel at the European World Trade and Convention Center, starting on Sunday afternoon (September 13) with the Registration and Inaugural Lecture. The scientific programme will take 
place from Monday morning (September 14) until Thursday (September 17).

\section{Conference Language}

The official language of the Symposium will be English.

Chairman of the Organizing Committee

E. Kyburz $(\mathrm{CH})$

Chairman of the Scientific Committee

B. Testa $(\mathrm{CH})$

\section{Scientific Programme}

The programme will focus on a number of selected themes of curren significance. These will be covered in one inaugural lecture, 4 plenary lectures and 36 main lectures. Special therapeutic areas as well as general methodological approaches will be presented.

Specialized themes according to mechanisms of action:

- Proteases and their inhibitors

- The immune system as a drug target

- Peptidomimetics acting on peptide receptors

- Agents affecting post-receptors events

- Selected enzyme inhibitors

- Drugs acting on neurotransmitter systems

- Drugs acting on nucleic acids and nucleic acid processing enzymes

- Ion channel modulators

General themes:

- Exciting new topics

- Approaches in lead finding and lead optimization

- Molecular toxicology

- Prodrugs and targeted drug delivery

All correspondence should be addressed to:

XIIth International Symposium on Medicinal Chemistry, Administrative Secretariat, P.O. Box 141, CH-4007 Basel, Switzerland.

\section{Schweizerisches Komitee für Chemie}

Comité Suisse de la Chimie

\section{Jahresbericht 1991}

\section{$(1.10 .90-30.9 .91)$}

Delegiertenversammlungen wurden am 29. Oktober 1990 in Fribourg und am 1. März 1991 in Bern abgehalten.

\section{Mutationen}

Dr. A.F. Leuenherger wurde als Nachfolger von Dr. A. Bodmer zum neuen Präsidenten der SGCl gewählt.

Mme Dr. Michelle Rossier wurde als Nachfolgerin von Prof. W. Riesen neue Präsidentin der SGKC.

Dr. D. Hauser wurde als neuer Delegierter der SCG im CSC ernannt.

\section{Strukturänderung CSC}

Am 31. Januar 1991 fand in Fribourg eine Sondersitzung des CSC statt, an der über den Stand der 'Fusionsverhandlungen' SCG/SChV informiert wurde, sowie eine Aussprache über die Zukunft der andern Mitgliedgesellschaften, die Zukunft des CSC und die Beziehungen zu den Akademien gehalten wurde.

\section{Internationale Beziehungen}

\section{FECS (Federation of European Chemical Societies)}

Anlässlich der Generalversammlung vom 25. Juni 1991 in London wurde Dr. R. Darms mit Wirkung vom 1. Juli 1992 als Nachfolger von Dr. W. Fritsche (GDCh) zum neuen Vorsitzenden der FECS gewählt.

Council Meetings fanden am 14./15. März 1991 in Potsdam und am 24. Juni 1991 in London statt. Dr. R. Darms nahm als Council-Mitglied an beiden Sitzungen teil.
Am Meeting der Working Party on Professional Affairs vom 19. Oktober 1990 in Luzern nahm Dr. U. Gruntz teil.

Dr. R. Battaglia besuchte die Jahressitzung der Working Party on Food Chemistry vom 20./21. September 1991 in Hamburg.

\section{IUPAC}

An der Generalversammlung vom 14./15. August in Hamburg nahmen Prof. W. v. Philipshorn, Prof. L.M. Venanzi und Prof. A. Fischli teil.

In der Kommission 'Chemistry and Industry' übernahm Prof. A. Fischli das Präsidium, während Dr. D. Wyrsch als National Representative die Schweiz vertritt.

\section{EUCHEM}

Am Meeting des EUCHEM Komitees vom 19. Oktober 1990 in Wien nahmen Prof. H. Dutler als Delegierter des CSC und Dr. R. Darms als Vertreter der FECS teil. Um Vorschläge für die zukünftige Gestaltung und Rolle der EUCHEM auszuarbeiten, wurde ein Executive Committee unter Leitung von Prof. H. Noth (GDCh) gebildet, dem auch Dr. R. Darms angehört.

\section{Chemie-Olympiade}

An der Chemie-Olympiade vom 7.-15. Juli 1991 in Lodz, Polen nahm erneut unter der Leitung von Dr. M. Cosandey eine Schülergruppe aus Schweizer-Gymnasiasten teil. Sie schnitt mit zwei Silbermedaillen sehr erfolgreich $a b$.

\section{Nationale Koordinationstätigkeit}

\section{KfU (Kommission für Unterrichtsfragen)}

Die von Prof. P. Müller geleitete Kommission 'Doktorate in der Chemie' hat einen Schlussbericht erstellt und damit ihre Tätigkeit abgeschlossen. Der Bericht wurde in der Chimia publiziert, sowie an Hochschulen und in der Industrie verteilt.

Die KfU hat mit der Ausarbeitung einer Konvention zur Förderung der Mobilität der Studierenden in der Chemie begonnen. Ein erster Entwurf liegt vor

\section{KfO (Kommission für Öffentlichkeitsarbeit)}

Die Beteiligung des CSC an der ILMAC 90 mit einer Vortragsveranstaltung war ein voller Erfolg. Das Programm, das von einer Kommission unter Leitung von Dr. A. Fürst ausgearbeitet wurde, war dem Thema 'Chemische Signale und ihre Empfänger' gewidmet. Mehr als 800 Personen, zum grössten Teil Jugendliche, haben daran teilgenommen. Zusätzlich zu einem Bericht in der Chimia wurde der Anlass auch in der Tagespresse sehr positiv beurteilt.

Im Rahmen der Kontakte 'Mittelschule-Hochschule' beteiligt sich die $\mathrm{KfO}$ an der Vorbereitung von Veranstaltungen, die zur Verringerurig der Abfallprobleme in Unterrichtslaboratorien beitragen sollten.

\section{IFS (Informationsstelle)}

Schwerpunkte der Tätigkeit der von Dr. U. Gruntz geleiteten IFS war wiederum die Erhebung der Statistik der Chemiestudierenden in der Schweiz. Als Erweiterung wurden auch Studierende der HTL in die Statistik aufgenommen.

\section{SANW}

An den Sitzungen des Zentralvorstandes hat Prof. U. Schlunegger teilgenommen. Obwohl sich in den Beziehungen des CSC zur SANW keine Schwierigkeiten ergeben, hat sich erneut gezeigt, dass die Chemie im Rahmen der SANW eine relativ beschränkte Unterstützung geniesst.

Für die '100 Jahr-Feier Genfer Chemie-Konferenz' im April 1992 wurde zusammen mit der SANW eine Sonderbriefmarke entworfen, die von der PTT auf diesen Anlass hin herausgegeben wird. Es wird dies erst die zweite Sonderbriefmarke auf dem Gebiete der Chemie in der Schweiz sein.

Prof. A. v. Zelew'sky

Präsident - CSC

Dr. $R$. Darms

Sekretär - CSC 
place from Monday morning (September 14) until Thursday (September 17).

\section{Conference Language}

The official language of the Symposium will be English.

Chairman of the Organizing Committee

E. Kyburz $(\mathrm{CH})$

Chairman of the Scientific Committee

B. Testa $(\mathrm{CH})$

\section{Scientific Programme}

The programme will focus on a number of selected themes of curren significance. These will be covered in one inaugural lecture, 4 plenary lectures and 36 main lectures. Special therapeutic areas as well as general methodological approaches will be presented.

Specialized themes according to mechanisms of action:

- Proteases and their inhibitors

- The immune system as a drug target

- Peptidomimetics acting on peptide receptors

- Agents affecting post-receptors events

- Selected enzyme inhibitors

- Drugs acting on neurotransmitter systems

- Drugs acting on nucleic acids and nucleic acid processing enzymes

- Ion channel modulators

General themes:

- Exciting new topics

- Approaches in lead finding and lead optimization

- Molecular toxicology

- Prodrugs and targeted drug delivery

All correspondence should be addressed to:

XIIth International Symposium on Medicinal Chemistry, Administrative Secretariat, P.O. Box 141, CH-4007 Basel, Switzerland.

\section{Schweizerisches Komitee für Chemie}

Comité Suisse de la Chimie

\section{Jahresbericht 1991}

\section{$(1.10 .90-30.9 .91)$}

Delegiertenversammlungen wurden am 29. Oktober 1990 in Fribourg und am 1. März 1991 in Bern abgehalten.

\section{Mutationen}

Dr. A.F. Leuenherger wurde als Nachfolger von Dr. A. Bodmer zum neuen Präsidenten der SGCl gewählt.

Mme Dr. Michelle Rossier wurde als Nachfolgerin von Prof. W. Riesen neue Präsidentin der SGKC.

Dr. D. Hauser wurde als neuer Delegierter der SCG im CSC ernannt.

\section{Strukturänderung CSC}

Am 31. Januar 1991 fand in Fribourg eine Sondersitzung des CSC statt, an der über den Stand der 'Fusionsverhandlungen' SCG/SChV informiert wurde, sowie eine Aussprache über die Zukunft der andern Mitgliedgesellschaften, die Zukunft des CSC und die Beziehungen zu den Akademien gehalten wurde.

\section{Internationale Beziehungen}

\section{FECS (Federation of European Chemical Societies)}

Anlässlich der Generalversammlung vom 25. Juni 1991 in London wurde Dr. R. Darms mit Wirkung vom 1. Juli 1992 als Nachfolger von Dr. W. Fritsche (GDCh) zum neuen Vorsitzenden der FECS gewählt.

Council Meetings fanden am 14./15. März 1991 in Potsdam und am 24. Juni 1991 in London statt. Dr. R. Darms nahm als Council-Mitglied an beiden Sitzungen teil.
Am Meeting der Working Party on Professional Affairs vom 19. Oktober 1990 in Luzern nahm Dr. U. Gruntz teil.

Dr. R. Battaglia besuchte die Jahressitzung der Working Party on Food Chemistry vom 20./21. September 1991 in Hamburg.

\section{IUPAC}

An der Generalversammlung vom 14./15. August in Hamburg nahmen Prof. W. v. Philipshorn, Prof. L.M. Venanzi und Prof. A. Fischli teil.

In der Kommission 'Chemistry and Industry' übernahm Prof. A. Fischli das Präsidium, während Dr. D. Wyrsch als National Representative die Schweiz vertritt.

\section{EUCHEM}

Am Meeting des EUCHEM Komitees vom 19. Oktober 1990 in Wien nahmen Prof. H. Dutler als Delegierter des CSC und Dr. R. Darms als Vertreter der FECS teil. Um Vorschläge für die zukünftige Gestaltung und Rolle der EUCHEM auszuarbeiten, wurde ein Executive Committee unter Leitung von Prof. H. Noth (GDCh) gebildet, dem auch Dr. R. Darms angehört.

\section{Chemie-Olympiade}

An der Chemie-Olympiade vom 7.-15. Juli 1991 in Lodz, Polen nahm erneut unter der Leitung von Dr. M. Cosandey eine Schülergruppe aus Schweizer-Gymnasiasten teil. Sie schnitt mit zwei Silbermedaillen sehr erfolgreich $a b$.

\section{Nationale Koordinationstätigkeit}

\section{KfU (Kommission für Unterrichtsfragen)}

Die von Prof. P. Müller geleitete Kommission 'Doktorate in der Chemie' hat einen Schlussbericht erstellt und damit ihre Tätigkeit abgeschlossen. Der Bericht wurde in der Chimia publiziert, sowie an Hochschulen und in der Industrie verteilt.

Die KfU hat mit der Ausarbeitung einer Konvention zur Förderung der Mobilität der Studierenden in der Chemie begonnen. Ein erster Entwurf liegt vor

\section{KfO (Kommission für Öffentlichkeitsarbeit)}

Die Beteiligung des CSC an der ILMAC 90 mit einer Vortragsveranstaltung war ein voller Erfolg. Das Programm, das von einer Kommission unter Leitung von Dr. A. Fürst ausgearbeitet wurde, war dem Thema 'Chemische Signale und ihre Empfänger' gewidmet. Mehr als 800 Personen, zum grössten Teil Jugendliche, haben daran teilgenommen. Zusätzlich zu einem Bericht in der Chimia wurde der Anlass auch in der Tagespresse sehr positiv beurteilt.

Im Rahmen der Kontakte 'Mittelschule-Hochschule' beteiligt sich die $\mathrm{KfO}$ an der Vorbereitung von Veranstaltungen, die zur Verringerurig der Abfallprobleme in Unterrichtslaboratorien beitragen sollten.

\section{IFS (Informationsstelle)}

Schwerpunkte der Tätigkeit der von Dr. U. Gruntz geleiteten IFS war wiederum die Erhebung der Statistik der Chemiestudierenden in der Schweiz. Als Erweiterung wurden auch Studierende der HTL in die Statistik aufgenommen.

\section{SANW}

An den Sitzungen des Zentralvorstandes hat Prof. U. Schlunegger teilgenommen. Obwohl sich in den Beziehungen des CSC zur SANW keine Schwierigkeiten ergeben, hat sich erneut gezeigt, dass die Chemie im Rahmen der SANW eine relativ beschränkte Unterstützung geniesst.

Für die '100 Jahr-Feier Genfer Chemie-Konferenz' im April 1992 wurde zusammen mit der SANW eine Sonderbriefmarke entworfen, die von der PTT auf diesen Anlass hin herausgegeben wird. Es wird dies erst die zweite Sonderbriefmarke auf dem Gebiete der Chemie in der Schweiz sein.

Prof. A. v. Zelew'sky

Präsident - CSC

Dr. $R$. Darms

Sekretär - CSC 
Schweizerischer Chemiker-Verband

Schweizerische Chemische Gesellschaft

Association Suisse des Chimistes

Société Suisse de Chimie

Swiss Association of Chemists

Swiss Chemical Society

Preannouncement

6th International Seminar on

\section{Modern Synthetic Methods}

May 4/5, 1992, Interlaken, Switzerland

Chairman: Prof. Rolf Scheffold, University of Bern

Topics in Carbanion Chemistry

Topics in Carbohydrate Chemistry

The detailed programme will be available in Dezember 1991: Secretary's Office for Symposia

c/o Institute of Organic Chemistry, University of Bern

Freiestrasse 3

CH-3012 Bern

Tel. 0316543 11, Fax 031654499

Schweizerische Chemische Gesellschaft (SCG) Société Suisse de Chimie (SSC)

Anlässlich der Herbstversammlung der Schweizerischen Chemischen Gesellschaft wurde am 18. Oktober 1991 die Sektion Analytische Chemie (SACh) gegründet. Die SACh wird eine Untergruppe der Neuen Schweizerischen Chemischen Gesellschaft, die im April 1992 in Genf durch Vereinigung der alten Schweizerischen Chemischen Gesellschaft (SCG) und des Schweizerischen Chemiker-Verbandes (SChV) entsteht. Aus juristischen Gründen ist die SACh bis April 1992 Mitglied der alten SCG.

Die SACh will sich für die Analytische Chemie und anverwandte Disziplinen in der Schweiz einsetzen, die Ausbildung und Weiterbildung auf dem Gebiet fördern, Kontakte mit ausländischen Analytikern und Berufsgruppen herstellen, die Anliegen des Analytikers wo nötig in die Öffentlichkeit tragen und das Image der Analytischen Chemie ganz generell verbessern. Die SACh will die freundschaftlichen Beziehungen unter den Analytikern pflegen.

Mitglied der SACh kann werden, wer gleichzeitig Mitglied der SCG ist oder wird. Bis heute haben sich bereits über 100 Mitglieder für die SACh angemeldet. Auf Wunsch senden wir Interessierten gerne das Reglement der SACh zu.

Der Vorstand:

Prof. Dr. H.M. Widmer, Ciba-Geigy' AG, Basel

Dr. U. Spichiger, ETHZ, Zürich

Dr. F. Erni, Sandoz $A G$, Basel

Dr. E. Gassmann, Ciba-Geigy AG, Basel

Dr. W. Giger, EAWAG, Dübendorf

Prof. Dr. W. Haerdi, Université de Genève, Genève

Dr. E.P. Halder, Lonza SA, Visp

Dr. F. Heinzer, Ebnöther $A G$, Sempach-Station

Prof. Dr. U.P. Schlunegger, Universität Bern, Bern

Anmeldung als Mitglied

in die Sektion Analytische Chemie

Prix Galen für Neupogen

Ein Gremium hochkarätiger Wissenschaftler und Mediziner in Grossbritannien hat soeben unter dem Patronat von Reed Healthcare Publishing den englischen Galen-Preis des Jahres 1991 an das Medikament Neupogen ${ }^{\infty}$ vergeben. Dieser Forschungspreis erinnert an den bedeutenden griechisch-römischen Arzt Galen und stellt die höchste Auszeichnung eines Landes für ein Medikament dar.

Neupogen ${ }^{\infty}$ ist der Markenname der Wirksubstanz Filgrastim, einer Form von G-CSF oder des Granulozyten-Kolonie-stimulierendenFaktors, der mit gentechnischen Methoden hergestellt wird. Das innovative Medikament Neupogen stammt aus der Forschung der amerikanischen Biotechnologiefirma Amgen, Kalifornien; es wurde in Europa gemeinsam von Amgen und Roche klinisch weiterentwickelt.

G-CSF ist ein hämatopoetischer Wachstumsfaktor, welcher in kleinsten Mengen im menschlichen Körper vorkommt; er regt spezifisch die Bildung und Freisetzung von neutrophilen Granulozyten an. Neutrophile Granulozyten leisten einen wichtigen Beitrag bei der Abwehr von Infektionen.
Bei onkologischen Patienten führt eine zytotoxische Chemotherapie oft zu einer Neutropenie. Mit zunehmender Tiefe und Dauer der Neutropenien steigt die Anzahl der lebensbedrohlichen Infekte, die dann mit intensiven und kostspieligen Antibiotikatherapien behandelt werden müssen. Febrile Neutropenien führen aber auch oftmals zu einer Reduktion der Chemotherapiedosis oder zu einer Verschiebung des Chemotherapiezyklus. Neupogen ${ }^{\otimes}$ vermag die Bildung der neutrophilen Granulozyten spezifisch anzuregen und $\mathrm{zu}$ beschleunigen. $\mathrm{Da}-$ durch können Neutropenien und die damit verbunden Infektionen reduziert werden. Dieser hämatopoetische Wachstumsfaktor wird darüberhinaus dazu beitragen, dass onkologische Patienten weniger häufig lebensbedrohlichen Infektionen ausgesetzt sind und sie die hochdosierte und damit wirkungsvollere zytotoxische Chemotherapie zum geplanten Zeitpunkt erhalten können.

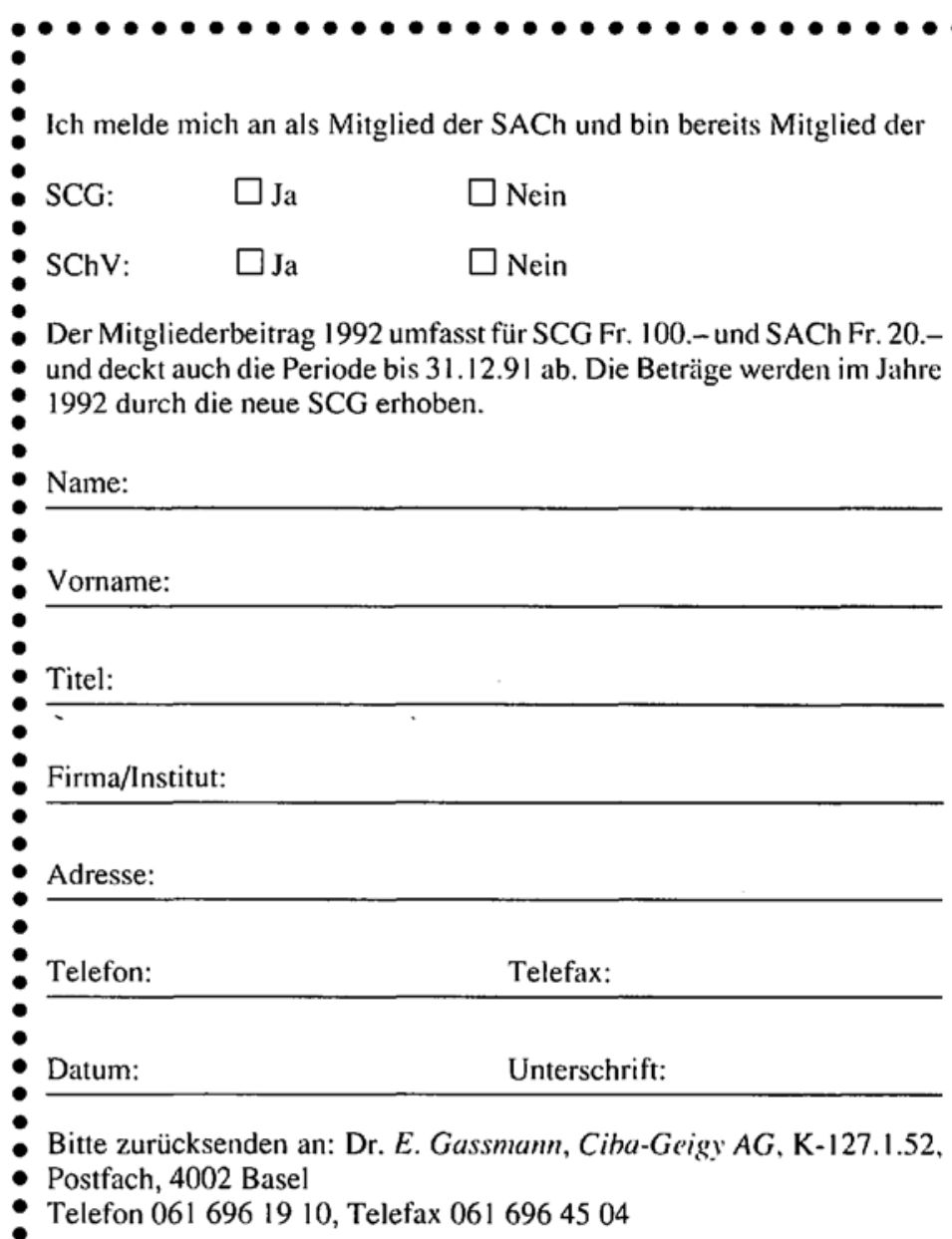

,

Ich melde mich an als Mitglied der SACh und bin bereits Mitglied der

SCG: $\quad \square$ Ja $\quad \square$ Nein

SChV: $\quad \square$ Ja $\quad \square$ Nein

Der Mitgliederbeitrag 1992 umfasst für SCG Fr. 100.-und SACh Fr. 20.und deckt auch die Periode bis 31.12.91 ab. Die Beträge werden im Jahre 1992 durch die neue SCG erhoben.

Name:

Vorname:

Titel:

Firma/Institut:

Adresse:

Telefon: Telefax:

Datum: Unterschrift:

Bitte zurücksenden an: Dr. E. Gassmann, Ciha-Geigy AG, K-127.1.52,

Postfach, 4002 Basel

- Telefon 06169619 10, Telefax 0616964504 
Schweizerischer Chemiker-Verband

Schweizerische Chemische Gesellschaft

Association Suisse des Chimistes

Société Suisse de Chimie

Swiss Association of Chemists

Swiss Chemical Society

Preannouncement

6th International Seminar on

\section{Modern Synthetic Methods}

May 4/5, 1992, Interlaken, Switzerland

Chairman: Prof. Rolf Scheffold, University of Bern

Topics in Carbanion Chemistry

Topics in Carbohydrate Chemistry

The detailed programme will be available in Dezember 1991: Secretary's Office for Symposia

c/o Institute of Organic Chemistry, University of Bern

Freiestrasse 3

CH-3012 Bern

Tel. 0316543 11, Fax 031654499

Schweizerische Chemische Gesellschaft (SCG) Société Suisse de Chimie (SSC)

Anlässlich der Herbstversammlung der Schweizerischen Chemischen Gesellschaft wurde am 18. Oktober 1991 die Sektion Analytische Chemie (SACh) gegründet. Die SACh wird eine Untergruppe der Neuen Schweizerischen Chemischen Gesellschaft, die im April 1992 in Genf durch Vereinigung der alten Schweizerischen Chemischen Gesellschaft (SCG) und des Schweizerischen Chemiker-Verbandes (SChV) entsteht. Aus juristischen Gründen ist die SACh bis April 1992 Mitglied der alten SCG.

Die SACh will sich für die Analytische Chemie und anverwandte Disziplinen in der Schweiz einsetzen, die Ausbildung und Weiterbildung auf dem Gebiet fördern, Kontakte mit ausländischen Analytikern und Berufsgruppen herstellen, die Anliegen des Analytikers wo nötig in die Öffentlichkeit tragen und das Image der Analytischen Chemie ganz generell verbessern. Die SACh will die freundschaftlichen Beziehungen unter den Analytikern pflegen.

Mitglied der SACh kann werden, wer gleichzeitig Mitglied der SCG ist oder wird. Bis heute haben sich bereits über 100 Mitglieder für die SACh angemeldet. Auf Wunsch senden wir Interessierten gerne das Reglement der SACh zu.

Der Vorstand:

Prof. Dr. H.M. Widmer, Ciba-Geigy' AG, Basel

Dr. U. Spichiger, ETHZ, Zürich

Dr. F. Erni, Sandoz $A G$, Basel

Dr. E. Gassmann, Ciba-Geigy AG, Basel

Dr. W. Giger, EAWAG, Dübendorf

Prof. Dr. W. Haerdi, Université de Genève, Genève

Dr. E.P. Halder, Lonza SA, Visp

Dr. F. Heinzer, Ebnöther $A G$, Sempach-Station

Prof. Dr. U.P. Schlunegger, Universität Bern, Bern

Anmeldung als Mitglied

in die Sektion Analytische Chemie

Prix Galen für Neupogen

Ein Gremium hochkarätiger Wissenschaftler und Mediziner in Grossbritannien hat soeben unter dem Patronat von Reed Healthcare Publishing den englischen Galen-Preis des Jahres 1991 an das Medikament Neupogen ${ }^{\infty}$ vergeben. Dieser Forschungspreis erinnert an den bedeutenden griechisch-römischen Arzt Galen und stellt die höchste Auszeichnung eines Landes für ein Medikament dar.

Neupogen ${ }^{\infty}$ ist der Markenname der Wirksubstanz Filgrastim, einer Form von G-CSF oder des Granulozyten-Kolonie-stimulierendenFaktors, der mit gentechnischen Methoden hergestellt wird. Das innovative Medikament Neupogen stammt aus der Forschung der amerikanischen Biotechnologiefirma Amgen, Kalifornien; es wurde in Europa gemeinsam von Amgen und Roche klinisch weiterentwickelt.

G-CSF ist ein hämatopoetischer Wachstumsfaktor, welcher in kleinsten Mengen im menschlichen Körper vorkommt; er regt spezifisch die Bildung und Freisetzung von neutrophilen Granulozyten an. Neutrophile Granulozyten leisten einen wichtigen Beitrag bei der Abwehr von Infektionen.
Bei onkologischen Patienten führt eine zytotoxische Chemotherapie oft zu einer Neutropenie. Mit zunehmender Tiefe und Dauer der Neutropenien steigt die Anzahl der lebensbedrohlichen Infekte, die dann mit intensiven und kostspieligen Antibiotikatherapien behandelt werden müssen. Febrile Neutropenien führen aber auch oftmals zu einer Reduktion der Chemotherapiedosis oder zu einer Verschiebung des Chemotherapiezyklus. Neupogen ${ }^{\otimes}$ vermag die Bildung der neutrophilen Granulozyten spezifisch anzuregen und $\mathrm{zu}$ beschleunigen. $\mathrm{Da}-$ durch können Neutropenien und die damit verbunden Infektionen reduziert werden. Dieser hämatopoetische Wachstumsfaktor wird darüberhinaus dazu beitragen, dass onkologische Patienten weniger häufig lebensbedrohlichen Infektionen ausgesetzt sind und sie die hochdosierte und damit wirkungsvollere zytotoxische Chemotherapie zum geplanten Zeitpunkt erhalten können.

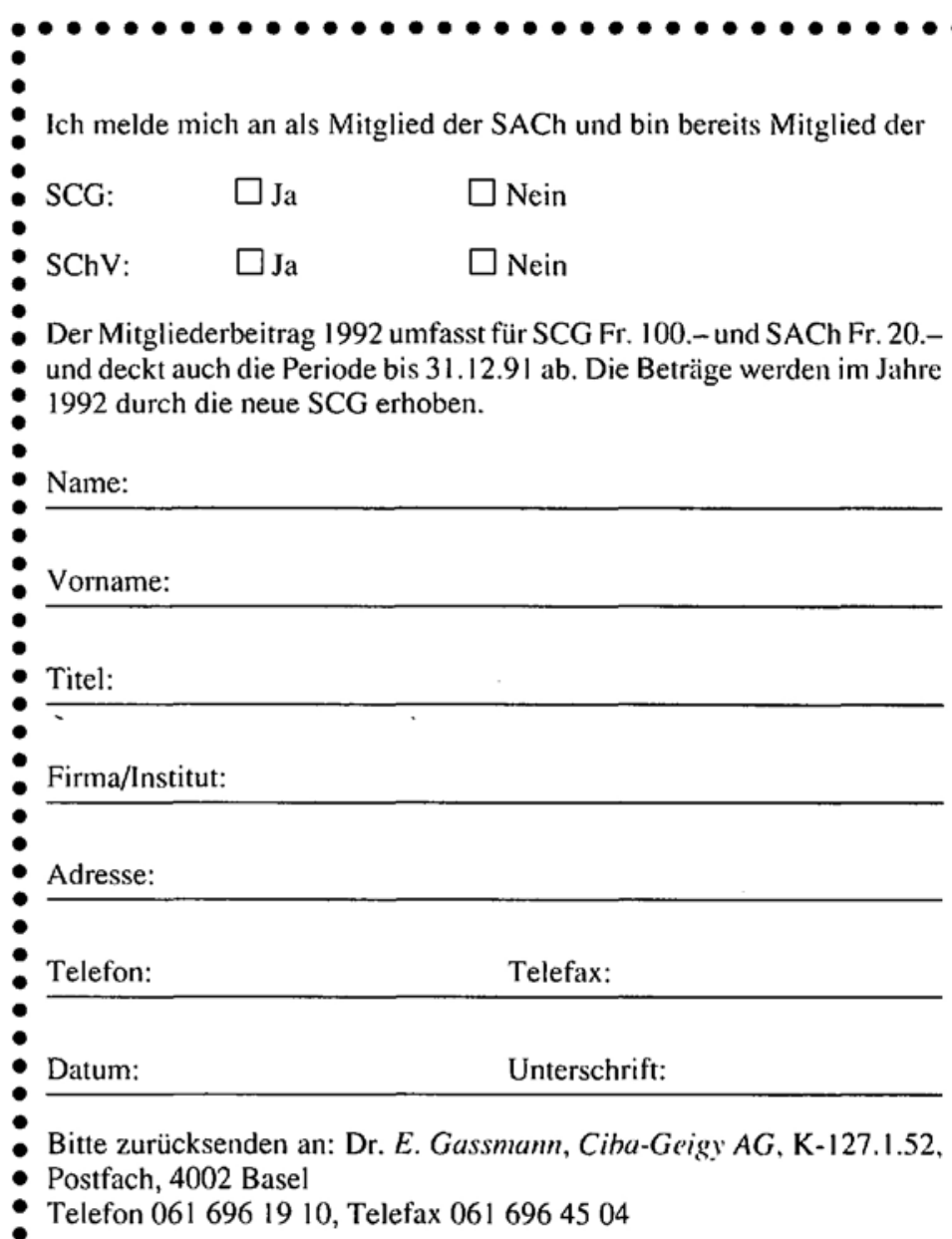

,

Ich melde mich an als Mitglied der SACh und bin bereits Mitglied der

SCG: $\quad \square$ Ja $\quad \square$ Nein

SChV: $\quad \square$ Ja $\quad \square$ Nein

Der Mitgliederbeitrag 1992 umfasst für SCG Fr. 100.-und SACh Fr. 20.und deckt auch die Periode bis 31.12.91 ab. Die Beträge werden im Jahre 1992 durch die neue SCG erhoben.

Name:

Vorname:

Titel:

Firma/Institut:

Adresse:

Telefon: Telefax:

Datum: Unterschrift:

Bitte zurücksenden an: Dr. E. Gassmann, Ciha-Geigy AG, K-127.1.52,

Postfach, 4002 Basel

- Telefon 06169619 10, Telefax 0616964504 
Schweizerischer Chemiker-Verband

Schweizerische Chemische Gesellschaft

Association Suisse des Chimistes

Société Suisse de Chimie

Swiss Association of Chemists

Swiss Chemical Society

Preannouncement

6th International Seminar on

\section{Modern Synthetic Methods}

May 4/5, 1992, Interlaken, Switzerland

Chairman: Prof. Rolf Scheffold, University of Bern

Topics in Carbanion Chemistry

Topics in Carbohydrate Chemistry

The detailed programme will be available in Dezember 1991: Secretary's Office for Symposia

c/o Institute of Organic Chemistry, University of Bern

Freiestrasse 3

CH-3012 Bern

Tel. 0316543 11, Fax 031654499

Schweizerische Chemische Gesellschaft (SCG) Société Suisse de Chimie (SSC)

Anlässlich der Herbstversammlung der Schweizerischen Chemischen Gesellschaft wurde am 18. Oktober 1991 die Sektion Analytische Chemie (SACh) gegründet. Die SACh wird eine Untergruppe der Neuen Schweizerischen Chemischen Gesellschaft, die im April 1992 in Genf durch Vereinigung der alten Schweizerischen Chemischen Gesellschaft (SCG) und des Schweizerischen Chemiker-Verbandes (SChV) entsteht. Aus juristischen Gründen ist die SACh bis April 1992 Mitglied der alten SCG.

Die SACh will sich für die Analytische Chemie und anverwandte Disziplinen in der Schweiz einsetzen, die Ausbildung und Weiterbildung auf dem Gebiet fördern, Kontakte mit ausländischen Analytikern und Berufsgruppen herstellen, die Anliegen des Analytikers wo nötig in die Öffentlichkeit tragen und das Image der Analytischen Chemie ganz generell verbessern. Die SACh will die freundschaftlichen Beziehungen unter den Analytikern pflegen.

Mitglied der SACh kann werden, wer gleichzeitig Mitglied der SCG ist oder wird. Bis heute haben sich bereits über 100 Mitglieder für die SACh angemeldet. Auf Wunsch senden wir Interessierten gerne das Reglement der SACh zu.

Der Vorstand:

Prof. Dr. H.M. Widmer, Ciba-Geigy' AG, Basel

Dr. U. Spichiger, ETHZ, Zürich

Dr. F. Erni, Sandoz $A G$, Basel

Dr. E. Gassmann, Ciba-Geigy AG, Basel

Dr. W. Giger, EAWAG, Dübendorf

Prof. Dr. W. Haerdi, Université de Genève, Genève

Dr. E.P. Halder, Lonza SA, Visp

Dr. F. Heinzer, Ebnöther $A G$, Sempach-Station

Prof. Dr. U.P. Schlunegger, Universität Bern, Bern

Anmeldung als Mitglied

in die Sektion Analytische Chemie

Prix Galen für Neupogen

Ein Gremium hochkarätiger Wissenschaftler und Mediziner in Grossbritannien hat soeben unter dem Patronat von Reed Healthcare Publishing den englischen Galen-Preis des Jahres 1991 an das Medikament Neupogen ${ }^{\infty}$ vergeben. Dieser Forschungspreis erinnert an den bedeutenden griechisch-römischen Arzt Galen und stellt die höchste Auszeichnung eines Landes für ein Medikament dar.

Neupogen ${ }^{\infty}$ ist der Markenname der Wirksubstanz Filgrastim, einer Form von G-CSF oder des Granulozyten-Kolonie-stimulierendenFaktors, der mit gentechnischen Methoden hergestellt wird. Das innovative Medikament Neupogen stammt aus der Forschung der amerikanischen Biotechnologiefirma Amgen, Kalifornien; es wurde in Europa gemeinsam von Amgen und Roche klinisch weiterentwickelt.

G-CSF ist ein hämatopoetischer Wachstumsfaktor, welcher in kleinsten Mengen im menschlichen Körper vorkommt; er regt spezifisch die Bildung und Freisetzung von neutrophilen Granulozyten an. Neutrophile Granulozyten leisten einen wichtigen Beitrag bei der Abwehr von Infektionen.
Bei onkologischen Patienten führt eine zytotoxische Chemotherapie oft zu einer Neutropenie. Mit zunehmender Tiefe und Dauer der Neutropenien steigt die Anzahl der lebensbedrohlichen Infekte, die dann mit intensiven und kostspieligen Antibiotikatherapien behandelt werden müssen. Febrile Neutropenien führen aber auch oftmals zu einer Reduktion der Chemotherapiedosis oder zu einer Verschiebung des Chemotherapiezyklus. Neupogen ${ }^{\otimes}$ vermag die Bildung der neutrophilen Granulozyten spezifisch anzuregen und $\mathrm{zu}$ beschleunigen. $\mathrm{Da}-$ durch können Neutropenien und die damit verbunden Infektionen reduziert werden. Dieser hämatopoetische Wachstumsfaktor wird darüberhinaus dazu beitragen, dass onkologische Patienten weniger häufig lebensbedrohlichen Infektionen ausgesetzt sind und sie die hochdosierte und damit wirkungsvollere zytotoxische Chemotherapie zum geplanten Zeitpunkt erhalten können.

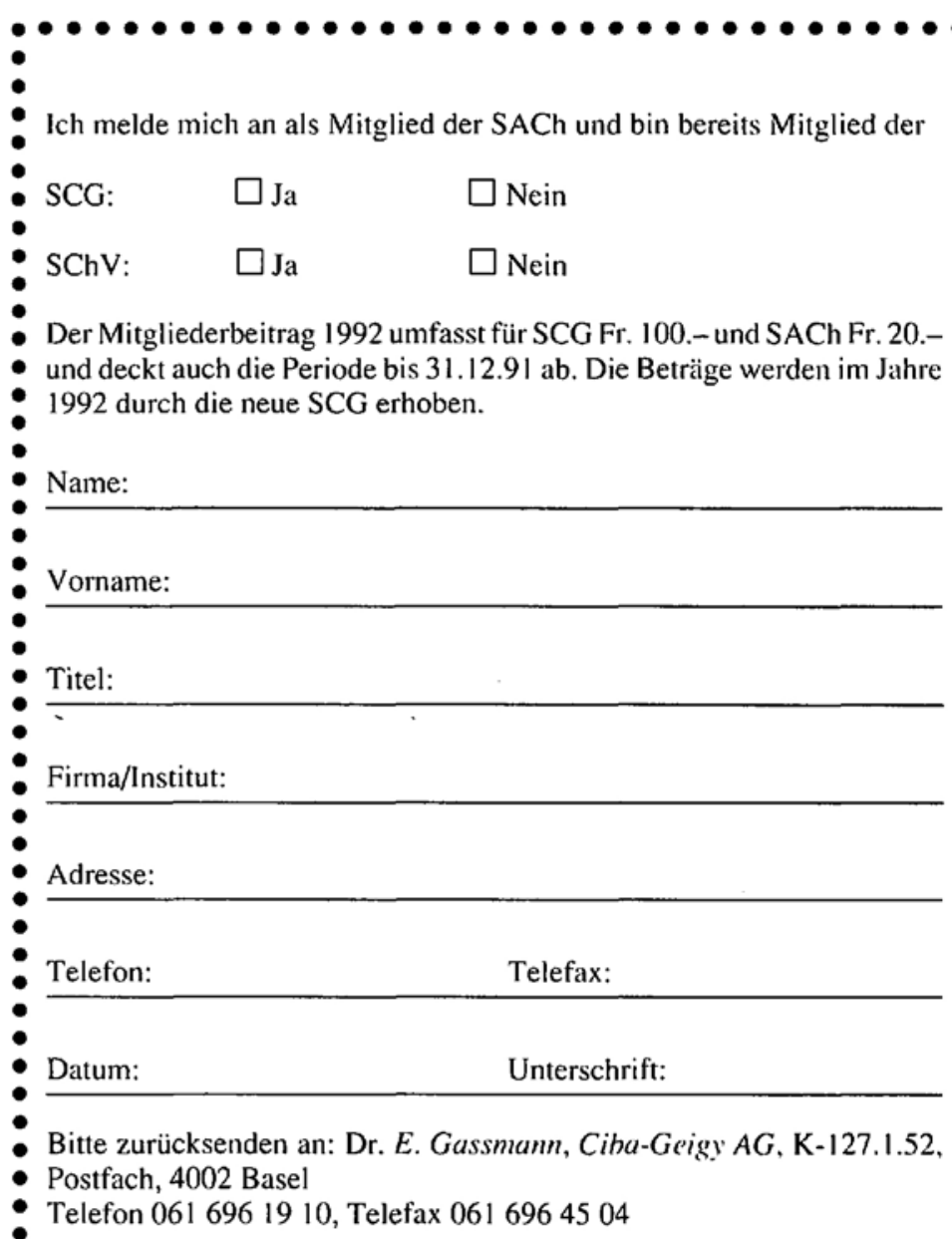

,

Ich melde mich an als Mitglied der SACh und bin bereits Mitglied der

SCG: $\quad \square$ Ja $\quad \square$ Nein

SChV: $\quad \square$ Ja $\quad \square$ Nein

Der Mitgliederbeitrag 1992 umfasst für SCG Fr. 100.-und SACh Fr. 20.und deckt auch die Periode bis 31.12.91 ab. Die Beträge werden im Jahre 1992 durch die neue SCG erhoben.

Name:

Vorname:

Titel:

Firma/Institut:

Adresse:

Telefon: Telefax:

Datum: Unterschrift:

Bitte zurücksenden an: Dr. E. Gassmann, Ciha-Geigy AG, K-127.1.52,

Postfach, 4002 Basel

- Telefon 06169619 10, Telefax 0616964504 
Schweizerische Chemische Gesellschaft (SCG) Société Suisse de Chimie (SSC)

Le 18 octobre 199I, lors de l'assemblée d'automne de la Société Chimique Suisse, a été fondée la Section Chimie Analytique (SACh). La SACh sera une sous-section de la nouvelle Société Chimique Suisse, laquelle résultera de la fusion en avril 1992 de l'ancienne Société Chimique Suisse (SCG) et de l'Union des Chimistes Suisses (SChV). Pour des raisons d'ordre juridique, la SACh sera, jusqu'à cette date, membre de l'anncienne SCG.

La SACh veut s'employer à promouvoir la chimie analytique et les disciplines apparentées en Suisse, encourager la formation et le recyclage dans ce domaine, établir des relations avec des chimistes analystes et leurs sociétés à l'étranger, rendre public les intérêts des analystes là où celà s'impose ainsi qu'améliorer l'image de la chimie analytique en général. La SACh entend aussi favoriser les relations amicales entre chimistes analystes.

Quiconque est ou devient membre de la SCG peut aussi devenir membre de la SACh. Nous comptons déjà plus de 100 personnes inscrites et serions heureux de faire parvenir le règlement de la $\mathrm{SACh}$ à toute personne intéressée.

Le comité directeur

22. Januar 1992

Prof. Dr. H.M. Widmer, Ciba-Geigy AG, Basel

Dr. U. Spichiger, ETHZ, Zürich

Dr. F. Erni, Sandoz AG, Basel

Dr. E. Gassmann, Ciba-Geigy AG, Basel

Dr. W. Giger, EAWAG, Dübendorf

Prof. Dr. W. Haerdi, Université de Genève, Genève

Dr. E.P. Halder, Lonza SA, Visp

Dr. F. Heinzer, Ebnöther AG, Sempach-Station

Prof. Dr. U.P. Schlunegger, Universität Bern, Bern

Vorträge

8. Januar 1992

15. Januar 1992

\section{Chemische Gesellschaft Zürich}

Mittwoch 17.15 Uhr

Hörsaal CAB D2 im Chemie Altbau ETH

Universitätstrasse 6, 8092 Zürich

Prof. Dr. E. Uhlig

Institut für Anorganische und Analytische

Chemie, Friedrich-Schiller Universität Jena, BRD

'NH-Acidität und Koordinationstendenz heterocyclischer 1,3-Diazaverbindungen'

Prof. Dr. H. Zimmermann

Institut für Physikalische Chemie Universität

Freiburg, Freiburg, BRD

'Über Farbstoffe als molekulare Sonden in lebenden Zellen'

Prof. Dr. R.J. Dav'ey

ICI Chemicals \& Polymers, Runcorn Cheshire, GB

'Crystal Morphology - its role in the design of surface active molecules'

29. Januar 1992 Prof. Dr. F.W. Röllgen

Institut für Physikalische und Theoretische

Chemie, Universität Bonn, Bonn, BRD

'Ionenbildung in der Thermospray- und

Elektrospray-Massenspektrometrie'

5. Februar $1992 \quad$ Prof. Dr. C. Mioskow'ski

Laboratoire de Chimie Bio-organique, Université

Louis Pasteur, Strasbourg, France

'Two-Dimensional Crystallization of DNA

Gyrase'

19. Februar 1992

Prof. Dr. F.N. Diederich

SChV:

$\square$ Oui

$\square$ Non

Pourl'année 1992, une cotisation de Fr. 100.-(SCG) et de Fr. 20.-(SACh) sera perçue. La période jusqu'au 31.12.199l est inclue dans ce montant. Les cotisations seront payables en 1992 à la nouvelle SCG.

Nom:

Prénom:

Titre:

Société/Institut:

Adresse:

Téléphone:

Téléfax:

Date:

Signature:

Prière de renvoyer à: Dr. E. Gassmann, Ciba-Geigy AG, K-127.1.52, Postfach, 4002 Bâle

Téléfone 06169619 10, Téléfax 0616964504

Departement of Chemistry and Biochemistry, University of California, Los Angeles, CA, USA

'Neuere Ergebnisse aus der Supramolekularen

Chemie: Lösungsmittel-Effekte, Chirale

Erkennung und Biomimetische Katalyse'

Hörsaal EG 16

Chemische Institute, Freiestrasse 3, Bern

15. Januar 1992

Prof. J.D. Dunitz

Laboratorium für organische Chemie, ETH

Zürich, Zürich

'Phasenumwandlungen in molekularen Kristallen aus chemischer Sicht'

29. Januar 1992 Prof. H. Ursprung Departement des Innern

'Die Naturwissenschaften und die schweizerische Hochschulpolitik'

Gemeinsame Veranstaltung der Akademischen Kommission der Universität Bern, des Bernischen Hochschulvereins, der Berner Naturforschenden Gesellschaft und der Berner Chemischen Gesellschaft

12. Februar 1992

Prof. K. Wüthrich

Institut für Molekularbiologie und Biophysik, ETH Zürich, Zürich 
Schweizerische Chemische Gesellschaft (SCG) Société Suisse de Chimie (SSC)

Le 18 octobre 199I, lors de l'assemblée d'automne de la Société Chimique Suisse, a été fondée la Section Chimie Analytique (SACh). La SACh sera une sous-section de la nouvelle Société Chimique Suisse, laquelle résultera de la fusion en avril 1992 de l'ancienne Société Chimique Suisse (SCG) et de l'Union des Chimistes Suisses (SChV). Pour des raisons d'ordre juridique, la SACh sera, jusqu'à cette date, membre de l'anncienne SCG.

La SACh veut s'employer à promouvoir la chimie analytique et les disciplines apparentées en Suisse, encourager la formation et le recyclage dans ce domaine, établir des relations avec des chimistes analystes et leurs sociétés à l'étranger, rendre public les intérêts des analystes là où celà s'impose ainsi qu'améliorer l'image de la chimie analytique en général. La SACh entend aussi favoriser les relations amicales entre chimistes analystes.

Quiconque est ou devient membre de la SCG peut aussi devenir membre de la SACh. Nous comptons déjà plus de 100 personnes inscrites et serions heureux de faire parvenir le règlement de la $\mathrm{SACh}$ à toute personne intéressée.

Le comité directeur

22. Januar 1992

Prof. Dr. H.M. Widmer, Ciba-Geigy AG, Basel

Dr. U. Spichiger, ETHZ, Zürich

Dr. F. Erni, Sandoz AG, Basel

Dr. E. Gassmann, Ciba-Geigy AG, Basel

Dr. W. Giger, EAWAG, Dübendorf

Prof. Dr. W. Haerdi, Université de Genève, Genève

Dr. E.P. Halder, Lonza SA, Visp

Dr. F. Heinzer, Ebnöther AG, Sempach-Station

Prof. Dr. U.P. Schlunegger, Universität Bern, Bern

Vorträge

8. Januar 1992

15. Januar 1992

\section{Chemische Gesellschaft Zürich}

Mittwoch 17.15 Uhr

Hörsaal CAB D2 im Chemie Altbau ETH

Universitätstrasse 6, 8092 Zürich

Prof. Dr. E. Uhlig

Institut für Anorganische und Analytische

Chemie, Friedrich-Schiller Universität Jena, BRD

'NH-Acidität und Koordinationstendenz heterocyclischer 1,3-Diazaverbindungen'

Prof. Dr. H. Zimmermann

Institut für Physikalische Chemie Universität

Freiburg, Freiburg, BRD

'Über Farbstoffe als molekulare Sonden in lebenden Zellen'

Prof. Dr. R.J. Dav'ey

ICI Chemicals \& Polymers, Runcorn Cheshire, GB

'Crystal Morphology - its role in the design of surface active molecules'

29. Januar 1992 Prof. Dr. F.W. Röllgen

Institut für Physikalische und Theoretische

Chemie, Universität Bonn, Bonn, BRD

'Ionenbildung in der Thermospray- und

Elektrospray-Massenspektrometrie'

5. Februar $1992 \quad$ Prof. Dr. C. Mioskow'ski

Laboratoire de Chimie Bio-organique, Université

Louis Pasteur, Strasbourg, France

'Two-Dimensional Crystallization of DNA

Gyrase'

19. Februar 1992

Prof. Dr. F.N. Diederich

SChV:

$\square$ Oui

$\square$ Non

Pourl'année 1992, une cotisation de Fr. 100.-(SCG) et de Fr. 20.-(SACh) sera perçue. La période jusqu'au 31.12.199l est inclue dans ce montant. Les cotisations seront payables en 1992 à la nouvelle SCG.

Nom:

Prénom:

Titre:

Société/Institut:

Adresse:

Téléphone:

Téléfax:

Date:

Signature:

Prière de renvoyer à: Dr. E. Gassmann, Ciba-Geigy AG, K-127.1.52, Postfach, 4002 Bâle

Téléfone 06169619 10, Téléfax 0616964504

Departement of Chemistry and Biochemistry, University of California, Los Angeles, CA, USA

'Neuere Ergebnisse aus der Supramolekularen

Chemie: Lösungsmittel-Effekte, Chirale

Erkennung und Biomimetische Katalyse'

Hörsaal EG 16

Chemische Institute, Freiestrasse 3, Bern

15. Januar 1992

Prof. J.D. Dunitz

Laboratorium für organische Chemie, ETH

Zürich, Zürich

'Phasenumwandlungen in molekularen Kristallen aus chemischer Sicht'

29. Januar 1992 Prof. H. Ursprung Departement des Innern

'Die Naturwissenschaften und die schweizerische Hochschulpolitik'

Gemeinsame Veranstaltung der Akademischen Kommission der Universität Bern, des Bernischen Hochschulvereins, der Berner Naturforschenden Gesellschaft und der Berner Chemischen Gesellschaft

12. Februar 1992

Prof. K. Wüthrich

Institut für Molekularbiologie und Biophysik, ETH Zürich, Zürich 
'NMR-Strukturen von Proteinen in Lösung' Gemeinsame Veranstaltung der Interfakultären Biochemie und der Berner Chemischen Gesellschaft.

\section{Organisch-Chemisches Institut der Universität Zürich}

Dienstag 17.15 Uhr

Hörsaal 91

$\begin{array}{ll}\text { 7. Januar } 1992 & \text { Dr.J.Kalvoda } \\ \text { Ciba-Geigy } A G, \text { Basel } \\ \text { 'Template Assembled Surface Mimics' }\end{array}$

14. Januar 1992

Prof. Dr. K. Bock

Carlsberg Laboratories, Valby Kopenhagen, Dänemark

'A General Approach to Solid Phase Synthesis of $\mathrm{O}$ - and $\mathrm{N}$-linked Glycopeptides'

28. Januar 1992

PD Dr. H.-J. Borschberg

Laboratorium für org. Chemie, ETH-Zentrum, Zürich

'Aristotelia Alkaloide: Synthetische und biomimetische Studien'

25. Februar $1992 \quad$ Dr. S. Withers

Laboratory of Molecular Biophysics, Oxford

Titel noch ausstehend

\section{Laboratorium für Organische Chemie der ETH-Zürich}

Organisch-chemische Kolloquien

Montag 16.30 Uhr

Hörsaal CHN A 31

Universitätstrasse 16,8092 Zürich

6. Januar 1992

Dr. J.-P. Sauvage

Université Louis Pasteur, Lab. de Chimie

Organo-Minérale, Strasbourg, France

'From entwined transition metal complexes to multiring interlocked systems and molecular knots'

13. Januar 1992

Dr. M. Banwell

University of Melboume, Parkville, Australia (z.Z. ETH Zürich)

'New Methods for the Synthesis of Troponoid Compounds'

20. Januar 1992

PD Dr. H.-J. Borschberg

ETH Zürich, Laboratorium für org. Chemie, Zürich

'Aristotelia Alkaloide: Synthetische und Biomimetische Studien'

27. Januar 1992 Prof, Dr. F. Vögtle Universität Bonn, Fachgruppe Chemie, Bonn BRD

(Thema noch unbestimmt)

3. Februar 1992 Prof. Dr. St.F. Mason

Cambridge, GB

'The Origins of Biomolecular Handedness' (gemeinsames Kolloquium der Institute für organische Chemie und physikalische Chemie)

10. Februar 1992 Prof. Dr. B. Kräutler

Universität Innsbruck, Institut für Org. u. Pharm. Chemie, Innsbruck, A

'Ein chemischer Beitrag zur Problematik des Chlorophyllabbaus'
24. Februar 1992

Prof. Dr. C. Still

Columbia University, Department of Chemistry, New York, NY, USA

'Synthetic Receptors for Peptides'

\section{Laboratorium für Anorganische Chemie der ETH-Zürich}

Koordinationschemie und homogene Katalyse

Mittwoch 9.00-15.15 Uhr

Hörsaal CAB B9

Universitätstrasse 6

8. Januar 1992

Prof. F. Calderazzo

University of Pisa, Pisa

'Organometallic Compounds of Palladium,

Platinum and Gold'

29. Januar 1992 Prof. P. Hofmann

Technische Universität, München

'Massgeschneiderte Komplexe der Nickel-Tirade zur selektiven Bindungsaktivierung organischer Moleküle'

11. Februar 1992 Prof. D. Astruc

University of Bordeaux I, Bordeaux

'Transition Metal Sandwiches as Electron and

Proton Reservoirs Towards Supramolecular

Organometallic Chemistry'

\section{Laboratoirum für Physikalische Chemie der ETH-Zürich}

Competence Center in Computational Chemistry $\mathrm{C} 4$

Hörsaal CHN E7

Universitätstrasse 22 (wenn nicht anders vermerkt)

9. Januar $1992 \quad$ Dr. M. Dölg

Donnertag, 17.30 Uhr Institut für Theoretische Chemie, Universität Stuttgart, Stuttgart

'Quasirelativistic Energy - adjusted ab initio

Pseudopotentials: Quantum Chemical Investigations of Rare Earth Compounds?

28. Januar 1992

Dienstag, 17.15 Uhr Institut für Organische Chemie, Technische

Universität, Berlin

(Thema wird noch bekanntgegeben)

(gemeinsam mit dem Kolloquium für Physikalische Chemie)

5. Februar $1992 \quad$ Prof. G. Folkers

Mittwoch, 17.15 Uhr Departement Pharmazie, ETH-Zürich, Zürich

Audi max, ETH 'Theriak und Transputer - Die Dynamik der

Pharmazeutischen Chemie'

(Einführungsvorlesung Auditorium Max., ETH

Hauptgebäude)

6. Februar $1992 \quad$ Dr. O. Gunnarsson

Donnerstag, 17.30 Uhr Max-Planck-Institut für Festkörperforschung, Stuttgart

'Chemical shifts and line shapes of $\mathrm{Cu} 2 \mathrm{p}$ core spectra for monovalent, divalent, and trivalent copper compounds'

\section{Februar $1992 \quad$ Prof. G. Folkers}

Donnerstag, 17.30 Uhr Departement Pharmazie, ETH-Zürich, Zürich Modellierung von Wechselwirkungskomplexen viraler Kinasen - Ansätze zur Entwicklung antiviraler und zytostatischer Arzneistoffe'

25. Februar 1992

Dr. J. Sauer

Dienstag, 17.15 Uhr Zentralinstitut für Physikalische Chemie, Berlin 'Modellierung aktiver Zentren und elementare Prozesse an Katalysatoroberflächen' (gemeinsam mit dem Kolloquium für Physikalische Chemie) 


\section{Institut für Polymere der ETH-Zürich}

Mittwoch 16.15 Uhr

Der Hörsaal CAB D28 befindet sich an der Universitätstrasse 6, dagegen ML II D28 im Maschinenlabor, Eingang Tannenstrasse!

22. Januar 1992 CAB D28

29. Januar 1992

CAB D28

5. Februar 1992 CAB D28

12. Februar 1992 ML II D28

19. Februar 1992 CAB D28

26. Februar 1992 CAB D28
Prof. Dr. W. Michaeli

Rheinisch-Westfälische Technische Hochschule, Aachen

'Notwendigkeiten und Chancen der Prozess-

Simulation in der Kunststoffverarbeitung'

\section{Prof. Dr. J. Schurz}

Karl-Franzens-Universität, Graz

'Rheologische Studien an Synovialflüssigkeiten'

Prof. Dr. H.-G. Kilian

Abt. Physik, Universität Ulm, Ulm

'Nichtlineares Zeitverhalten in Permanenten

Netzwerken als lineare Antwort im Sinne der

Thermodynamik Irreversibler Prozesse'

Dr. G. Riess

Ecole Nationale Supérieure de Chimie,

Mulhouse

'Anwendung von Blockcopolymeren als

Compatibilizer in Polymermischungen'

\section{Prof. Dr. C.W. Schläpfer}

Inst. für Anorg. Chemie, Univ. Fribourg, Fribourg

'Polymere als Liganden: die Komplexbildung PEI (Polyetherimine) mit Übergangsmetallionen'

Prof. Dr. G. Prota

Facultà di Science, Univ. di Napoli, Napoli

'The Chemistry of Melamine Skin Pigmentation' ten Produkte jedoch getrennt vermarkten. Die Zusammenarbeit betrifft die Erforschung von Serotonin, einer Substanz, die als Neurotransmitter für die Signalübertragung im Gehirn und anderen Organen wichtig ist. Neue Präparate aus der gemeinsamen pharmazeutischen Forschung sollen auf ihre mögliche Anwendung bei der Behandlung von Depressionen, Angstzuständen, Schizophrenie und verwandten Erkrankungen hin untersucht werden. Trotz der in den vergangenen Jahren erzielten Erfolge besteht noch genügend Raum für eine wesentliche Verbesserung in der Behandlung dieser Krankheiten.

Ehrungen

\section{Akademische Ehrungen}

Der Louisa Gross Horwitz Prize for Biology or Biochemistry 1991 der Columbia University wurde am 17. Oktober in New York den beiden ETH-Professoren Dr. Richard $R$. Ernst, Professor derETHZürich für Physikalische Chemie, und Dr. Kurt Wüthrich, Professor der ETH Zürich für Biophysik, verliehen für ihre Pionierbeiträge zur Entwicklung und Anwendung der Kernresonanzspektroskopie in der dreidimensionalen Strukturbestimmung biologischer Makromoleküle in Lösung.

Prof. Dr. Heinrich Zollinger, Professor der ETH Zürich im Ruhestand, wurde zum Honorary Fellow des Shenkar College of Textile
Technology and Fashion (Höhere Technische Lehranstalt Israels für alle Bereiche der Textiltechnologie) in Ramat-Gan, Israel, ernannt.

Daniel Bellus, Prof. Dr. Dipl.-Ing., Leiter des Konzernbereichs Forschung der Firma Ciba-Geigy $A G$, Basel, wurde in Anerkennung seiner 'originellen Beiträge zur industriellen organischen und bioorganischen Synthese sowie zur modernen Photochemie' mit der Ehrendoktorwürde der Slowakischen Technischen Universität, Bratislava, und mit der Gold-Gedächtnismedaille der Comenius Universität in Bratislava ausgezeichnet.

\section{Bücher}

\section{Sigma-Tau und Roche schliessen ein wichtiges}

\section{Abkommen über Acetyl-L-Carnitin}

Die italienische FirmaSigma-Tau S.p.A. mit Sitz in Rom und $F$. Hoffmann-La Roche AG, Basel, haben soeben einen Vertrag unterzeichnet, der Roche das Recht auf die weltweite Registrierung und Vermarktung der Sigma-Tau-Wirksubstanz Acetyl-L-Carnitin einräumt. Der Vertrag regelt auch die künftige medizinische Entwicklung, die zum Teil mit weiteren Partnern von Sigma-Tau und mit Sigma-Tau selbst erfolgen wird. Das sehr gut verträgliche Arzneimittel auf Basis einer Natursubstanz hat in klinischen Studien der Phase II in Europa positive Wirkungen bei Patienten mit Alzheimer'scher Krankheit gezeigt.

In den USA wurde dieses Jahr an 27 Forschungszentren eine gross multizentrische Studie der Phase Il mit 400 Alzheimer-Patienten begonnen, die für ein Jahr mit AcetylL-Carnitin behandelt werden sollen. Daneben wurden in den USA zwe weitere klinische Prüfungen durchgeführt; die eine Studie an der $\mathrm{Col}$ umbia University, New York, wurde soeben fertiggestellt, die andere wird an der Stanford University, Palo Alto, Kalifornien, demnächst beendet. Als zusätzliche Einsatzgebiete für Acetyl-L-Carnitin werden gegenwärtig auch periphere Nervenschäden sowie Komazustände in tensiv erforscht.

\section{Roche und Organon schliessen Forschungsabkommen}

Organon International B.V., ein Geschäftszweig der Pharma Division von $A k z o$ in Oss, Niederlande, und die $F$. Hoffmann-La Roche AG in Basel haben ein Abkommen geschlossen, das künftig die gemeinsame Forschung und Entwicklung neuer Medikamente zur Behandlung von bestimmten psychischen Erkrankungen vorsieht. Die weltweiten Rechte an allen aus der geplanten Zusammenarbeit resultierenden Produkten werden sowohl von $R O$ che als auch von Organon wahrgenommen. Die beiden Unternehmen werden die gemeinsam entwickel-

\section{Bei der Redaktion eingetroffene Bücher}

\section{R.G. Wilkins}

'Kinetics and Mechanism of Reactions of Transition Metal Complexes'

2nd Thoroughly Revised Edition $\mathrm{VCH}$ Verlagsgesellschaft $\mathrm{mbH}$, Weinheim, 1991

GBF Monographs Volume 15

'Protein Glycosylation: Cellular. Biotechnological and Analytical Aspects'

Ed. by H.S. Conratd

VCH Verlagsgesellschaft $\mathrm{mbH}$,

Weinheim, 1991

\section{Personalia}

\section{Neue Mitglieder}

Jörg Herrmann

Dipl. Chem. ETH, Wartburgstrasse 16, 4663 Aarburg

Fabian Perroud

Dipl. Chem. HTL, Baderstrasse 6, 8400 Winterthur
S. Hauptmann

'Organische Chemie'

3., unveränderte Aufl.

Deutscher Verlag für Grundstoffindustrie $\mathrm{GmbH}$, Leipzig, 1991
Otmar Zoller

Dr. sc. nat. ETH, Schützenstrasse 33, 3097 Liebefeld 


\section{Institut für Polymere der ETH-Zürich}

Mittwoch 16.15 Uhr

Der Hörsaal CAB D28 befindet sich an der Universitätstrasse 6, dagegen ML II D28 im Maschinenlabor, Eingang Tannenstrasse!

22. Januar 1992 CAB D28

29. Januar 1992

CAB D28

5. Februar 1992 CAB D28

12. Februar 1992 ML II D28

19. Februar 1992 CAB D28

26. Februar 1992 CAB D28
Prof. Dr. W. Michaeli

Rheinisch-Westfälische Technische Hochschule, Aachen

'Notwendigkeiten und Chancen der Prozess-

Simulation in der Kunststoffverarbeitung'

\section{Prof. Dr. J. Schurz}

Karl-Franzens-Universität, Graz

'Rheologische Studien an Synovialflüssigkeiten'

Prof. Dr. H.-G. Kilian

Abt. Physik, Universität Ulm, Ulm

'Nichtlineares Zeitverhalten in Permanenten

Netzwerken als lineare Antwort im Sinne der

Thermodynamik Irreversibler Prozesse'

Dr. G. Riess

Ecole Nationale Supérieure de Chimie,

Mulhouse

'Anwendung von Blockcopolymeren als

Compatibilizer in Polymermischungen'

\section{Prof. Dr. C.W. Schläpfer}

Inst. für Anorg. Chemie, Univ. Fribourg, Fribourg

'Polymere als Liganden: die Komplexbildung PEI (Polyetherimine) mit Übergangsmetallionen'

Prof. Dr. G. Prota

Facultà di Science, Univ. di Napoli, Napoli

'The Chemistry of Melamine Skin Pigmentation' ten Produkte jedoch getrennt vermarkten. Die Zusammenarbeit betrifft die Erforschung von Serotonin, einer Substanz, die als Neurotransmitter für die Signalübertragung im Gehirn und anderen Organen wichtig ist. Neue Präparate aus der gemeinsamen pharmazeutischen Forschung sollen auf ihre mögliche Anwendung bei der Behandlung von Depressionen, Angstzuständen, Schizophrenie und verwandten Erkrankungen hin untersucht werden. Trotz der in den vergangenen Jahren erzielten Erfolge besteht noch genügend Raum für eine wesentliche Verbesserung in der Behandlung dieser Krankheiten.

Ehrungen

\section{Akademische Ehrungen}

Der Louisa Gross Horwitz Prize for Biology or Biochemistry 1991 der Columbia University wurde am 17. Oktober in New York den beiden ETH-Professoren Dr. Richard $R$. Ernst, Professor derETHZürich für Physikalische Chemie, und Dr. Kurt Wüthrich, Professor der ETH Zürich für Biophysik, verliehen für ihre Pionierbeiträge zur Entwicklung und Anwendung der Kernresonanzspektroskopie in der dreidimensionalen Strukturbestimmung biologischer Makromoleküle in Lösung.

Prof. Dr. Heinrich Zollinger, Professor der ETH Zürich im Ruhestand, wurde zum Honorary Fellow des Shenkar College of Textile
Technology and Fashion (Höhere Technische Lehranstalt Israels für alle Bereiche der Textiltechnologie) in Ramat-Gan, Israel, ernannt.

Daniel Bellus, Prof. Dr. Dipl.-Ing., Leiter des Konzernbereichs Forschung der Firma Ciba-Geigy $A G$, Basel, wurde in Anerkennung seiner 'originellen Beiträge zur industriellen organischen und bioorganischen Synthese sowie zur modernen Photochemie' mit der Ehrendoktorwürde der Slowakischen Technischen Universität, Bratislava, und mit der Gold-Gedächtnismedaille der Comenius Universität in Bratislava ausgezeichnet.

\section{Bücher}

\section{Sigma-Tau und Roche schliessen ein wichtiges}

\section{Abkommen über Acetyl-L-Carnitin}

Die italienische FirmaSigma-Tau S.p.A. mit Sitz in Rom und $F$. Hoffmann-La Roche AG, Basel, haben soeben einen Vertrag unterzeichnet, der Roche das Recht auf die weltweite Registrierung und Vermarktung der Sigma-Tau-Wirksubstanz Acetyl-L-Carnitin einräumt. Der Vertrag regelt auch die künftige medizinische Entwicklung, die zum Teil mit weiteren Partnern von Sigma-Tau und mit Sigma-Tau selbst erfolgen wird. Das sehr gut verträgliche Arzneimittel auf Basis einer Natursubstanz hat in klinischen Studien der Phase II in Europa positive Wirkungen bei Patienten mit Alzheimer'scher Krankheit gezeigt.

In den USA wurde dieses Jahr an 27 Forschungszentren eine gross multizentrische Studie der Phase Il mit 400 Alzheimer-Patienten begonnen, die für ein Jahr mit AcetylL-Carnitin behandelt werden sollen. Daneben wurden in den USA zwe weitere klinische Prüfungen durchgeführt; die eine Studie an der $\mathrm{Col}$ umbia University, New York, wurde soeben fertiggestellt, die andere wird an der Stanford University, Palo Alto, Kalifornien, demnächst beendet. Als zusätzliche Einsatzgebiete für Acetyl-L-Carnitin werden gegenwärtig auch periphere Nervenschäden sowie Komazustände in tensiv erforscht.

\section{Roche und Organon schliessen Forschungsabkommen}

Organon International B.V., ein Geschäftszweig der Pharma Division von $A k z o$ in Oss, Niederlande, und die $F$. Hoffmann-La Roche AG in Basel haben ein Abkommen geschlossen, das künftig die gemeinsame Forschung und Entwicklung neuer Medikamente zur Behandlung von bestimmten psychischen Erkrankungen vorsieht. Die weltweiten Rechte an allen aus der geplanten Zusammenarbeit resultierenden Produkten werden sowohl von $R O$ che als auch von Organon wahrgenommen. Die beiden Unternehmen werden die gemeinsam entwickel-

\section{Bei der Redaktion eingetroffene Bücher}

\section{R.G. Wilkins}

'Kinetics and Mechanism of Reactions of Transition Metal Complexes'

2nd Thoroughly Revised Edition $\mathrm{VCH}$ Verlagsgesellschaft $\mathrm{mbH}$, Weinheim, 1991

GBF Monographs Volume 15

'Protein Glycosylation: Cellular. Biotechnological and Analytical Aspects'

Ed. by H.S. Conratd

VCH Verlagsgesellschaft $\mathrm{mbH}$,

Weinheim, 1991

\section{Personalia}

\section{Neue Mitglieder}

Jörg Herrmann

Dipl. Chem. ETH, Wartburgstrasse 16, 4663 Aarburg

Fabian Perroud

Dipl. Chem. HTL, Baderstrasse 6, 8400 Winterthur
S. Hauptmann

'Organische Chemie'

3., unveränderte Aufl.

Deutscher Verlag für Grundstoffindustrie $\mathrm{GmbH}$, Leipzig, 1991
Otmar Zoller

Dr. sc. nat. ETH, Schützenstrasse 33, 3097 Liebefeld 


\section{Institut für Polymere der ETH-Zürich}

Mittwoch 16.15 Uhr

Der Hörsaal CAB D28 befindet sich an der Universitätstrasse 6, dagegen ML II D28 im Maschinenlabor, Eingang Tannenstrasse!

22. Januar 1992 CAB D28

29. Januar 1992

CAB D28

5. Februar 1992 CAB D28

12. Februar 1992 ML II D28

19. Februar 1992 CAB D28

26. Februar 1992 CAB D28
Prof. Dr. W. Michaeli

Rheinisch-Westfälische Technische Hochschule, Aachen

'Notwendigkeiten und Chancen der Prozess-

Simulation in der Kunststoffverarbeitung'

\section{Prof. Dr. J. Schurz}

Karl-Franzens-Universität, Graz

'Rheologische Studien an Synovialflüssigkeiten'

Prof. Dr. H.-G. Kilian

Abt. Physik, Universität Ulm, Ulm

'Nichtlineares Zeitverhalten in Permanenten

Netzwerken als lineare Antwort im Sinne der

Thermodynamik Irreversibler Prozesse'

Dr. G. Riess

Ecole Nationale Supérieure de Chimie,

Mulhouse

'Anwendung von Blockcopolymeren als

Compatibilizer in Polymermischungen'

\section{Prof. Dr. C.W. Schläpfer}

Inst. für Anorg. Chemie, Univ. Fribourg, Fribourg

'Polymere als Liganden: die Komplexbildung PEI (Polyetherimine) mit Übergangsmetallionen'

Prof. Dr. G. Prota

Facultà di Science, Univ. di Napoli, Napoli

'The Chemistry of Melamine Skin Pigmentation' ten Produkte jedoch getrennt vermarkten. Die Zusammenarbeit betrifft die Erforschung von Serotonin, einer Substanz, die als Neurotransmitter für die Signalübertragung im Gehirn und anderen Organen wichtig ist. Neue Präparate aus der gemeinsamen pharmazeutischen Forschung sollen auf ihre mögliche Anwendung bei der Behandlung von Depressionen, Angstzuständen, Schizophrenie und verwandten Erkrankungen hin untersucht werden. Trotz der in den vergangenen Jahren erzielten Erfolge besteht noch genügend Raum für eine wesentliche Verbesserung in der Behandlung dieser Krankheiten.

Ehrungen

\section{Akademische Ehrungen}

Der Louisa Gross Horwitz Prize for Biology or Biochemistry 1991 der Columbia University wurde am 17. Oktober in New York den beiden ETH-Professoren Dr. Richard $R$. Ernst, Professor derETHZürich für Physikalische Chemie, und Dr. Kurt Wüthrich, Professor der ETH Zürich für Biophysik, verliehen für ihre Pionierbeiträge zur Entwicklung und Anwendung der Kernresonanzspektroskopie in der dreidimensionalen Strukturbestimmung biologischer Makromoleküle in Lösung.

Prof. Dr. Heinrich Zollinger, Professor der ETH Zürich im Ruhestand, wurde zum Honorary Fellow des Shenkar College of Textile
Technology and Fashion (Höhere Technische Lehranstalt Israels für alle Bereiche der Textiltechnologie) in Ramat-Gan, Israel, ernannt.

Daniel Bellus, Prof. Dr. Dipl.-Ing., Leiter des Konzernbereichs Forschung der Firma Ciba-Geigy $A G$, Basel, wurde in Anerkennung seiner 'originellen Beiträge zur industriellen organischen und bioorganischen Synthese sowie zur modernen Photochemie' mit der Ehrendoktorwürde der Slowakischen Technischen Universität, Bratislava, und mit der Gold-Gedächtnismedaille der Comenius Universität in Bratislava ausgezeichnet.

\section{Bücher}

\section{Sigma-Tau und Roche schliessen ein wichtiges}

\section{Abkommen über Acetyl-L-Carnitin}

Die italienische FirmaSigma-Tau S.p.A. mit Sitz in Rom und $F$. Hoffmann-La Roche AG, Basel, haben soeben einen Vertrag unterzeichnet, der Roche das Recht auf die weltweite Registrierung und Vermarktung der Sigma-Tau-Wirksubstanz Acetyl-L-Carnitin einräumt. Der Vertrag regelt auch die künftige medizinische Entwicklung, die zum Teil mit weiteren Partnern von Sigma-Tau und mit Sigma-Tau selbst erfolgen wird. Das sehr gut verträgliche Arzneimittel auf Basis einer Natursubstanz hat in klinischen Studien der Phase II in Europa positive Wirkungen bei Patienten mit Alzheimer'scher Krankheit gezeigt.

In den USA wurde dieses Jahr an 27 Forschungszentren eine gross multizentrische Studie der Phase Il mit 400 Alzheimer-Patienten begonnen, die für ein Jahr mit AcetylL-Carnitin behandelt werden sollen. Daneben wurden in den USA zwe weitere klinische Prüfungen durchgeführt; die eine Studie an der $\mathrm{Col}$ umbia University, New York, wurde soeben fertiggestellt, die andere wird an der Stanford University, Palo Alto, Kalifornien, demnächst beendet. Als zusätzliche Einsatzgebiete für Acetyl-L-Carnitin werden gegenwärtig auch periphere Nervenschäden sowie Komazustände in tensiv erforscht.

\section{Roche und Organon schliessen Forschungsabkommen}

Organon International B.V., ein Geschäftszweig der Pharma Division von $A k z o$ in Oss, Niederlande, und die $F$. Hoffmann-La Roche AG in Basel haben ein Abkommen geschlossen, das künftig die gemeinsame Forschung und Entwicklung neuer Medikamente zur Behandlung von bestimmten psychischen Erkrankungen vorsieht. Die weltweiten Rechte an allen aus der geplanten Zusammenarbeit resultierenden Produkten werden sowohl von $R O$ che als auch von Organon wahrgenommen. Die beiden Unternehmen werden die gemeinsam entwickel-

\section{Bei der Redaktion eingetroffene Bücher}

\section{R.G. Wilkins}

'Kinetics and Mechanism of Reactions of Transition Metal Complexes'

2nd Thoroughly Revised Edition $\mathrm{VCH}$ Verlagsgesellschaft $\mathrm{mbH}$, Weinheim, 1991

GBF Monographs Volume 15

'Protein Glycosylation: Cellular. Biotechnological and Analytical Aspects'

Ed. by H.S. Conratd

VCH Verlagsgesellschaft $\mathrm{mbH}$,

Weinheim, 1991

\section{Personalia}

\section{Neue Mitglieder}

Jörg Herrmann

Dipl. Chem. ETH, Wartburgstrasse 16, 4663 Aarburg

Fabian Perroud

Dipl. Chem. HTL, Baderstrasse 6, 8400 Winterthur
S. Hauptmann

'Organische Chemie'

3., unveränderte Aufl.

Deutscher Verlag für Grundstoffindustrie $\mathrm{GmbH}$, Leipzig, 1991
Otmar Zoller

Dr. sc. nat. ETH, Schützenstrasse 33, 3097 Liebefeld 


\section{Institut für Polymere der ETH-Zürich}

Mittwoch 16.15 Uhr

Der Hörsaal CAB D28 befindet sich an der Universitätstrasse 6, dagegen ML II D28 im Maschinenlabor, Eingang Tannenstrasse!

22. Januar 1992 CAB D28

29. Januar 1992

CAB D28

5. Februar 1992 CAB D28

12. Februar 1992 ML II D28

19. Februar 1992 CAB D28

26. Februar 1992 CAB D28
Prof. Dr. W. Michaeli

Rheinisch-Westfälische Technische Hochschule, Aachen

'Notwendigkeiten und Chancen der Prozess-

Simulation in der Kunststoffverarbeitung'

\section{Prof. Dr. J. Schurz}

Karl-Franzens-Universität, Graz

'Rheologische Studien an Synovialflüssigkeiten'

Prof. Dr. H.-G. Kilian

Abt. Physik, Universität Ulm, Ulm

'Nichtlineares Zeitverhalten in Permanenten

Netzwerken als lineare Antwort im Sinne der

Thermodynamik Irreversibler Prozesse'

Dr. G. Riess

Ecole Nationale Supérieure de Chimie,

Mulhouse

'Anwendung von Blockcopolymeren als

Compatibilizer in Polymermischungen'

\section{Prof. Dr. C.W. Schläpfer}

Inst. für Anorg. Chemie, Univ. Fribourg, Fribourg

'Polymere als Liganden: die Komplexbildung PEI (Polyetherimine) mit Übergangsmetallionen'

Prof. Dr. G. Prota

Facultà di Science, Univ. di Napoli, Napoli

'The Chemistry of Melamine Skin Pigmentation' ten Produkte jedoch getrennt vermarkten. Die Zusammenarbeit betrifft die Erforschung von Serotonin, einer Substanz, die als Neurotransmitter für die Signalübertragung im Gehirn und anderen Organen wichtig ist. Neue Präparate aus der gemeinsamen pharmazeutischen Forschung sollen auf ihre mögliche Anwendung bei der Behandlung von Depressionen, Angstzuständen, Schizophrenie und verwandten Erkrankungen hin untersucht werden. Trotz der in den vergangenen Jahren erzielten Erfolge besteht noch genügend Raum für eine wesentliche Verbesserung in der Behandlung dieser Krankheiten.

Ehrungen

\section{Akademische Ehrungen}

Der Louisa Gross Horwitz Prize for Biology or Biochemistry 1991 der Columbia University wurde am 17. Oktober in New York den beiden ETH-Professoren Dr. Richard $R$. Ernst, Professor derETHZürich für Physikalische Chemie, und Dr. Kurt Wüthrich, Professor der ETH Zürich für Biophysik, verliehen für ihre Pionierbeiträge zur Entwicklung und Anwendung der Kernresonanzspektroskopie in der dreidimensionalen Strukturbestimmung biologischer Makromoleküle in Lösung.

Prof. Dr. Heinrich Zollinger, Professor der ETH Zürich im Ruhestand, wurde zum Honorary Fellow des Shenkar College of Textile
Technology and Fashion (Höhere Technische Lehranstalt Israels für alle Bereiche der Textiltechnologie) in Ramat-Gan, Israel, ernannt.

Daniel Bellus, Prof. Dr. Dipl.-Ing., Leiter des Konzernbereichs Forschung der Firma Ciba-Geigy $A G$, Basel, wurde in Anerkennung seiner 'originellen Beiträge zur industriellen organischen und bioorganischen Synthese sowie zur modernen Photochemie' mit der Ehrendoktorwürde der Slowakischen Technischen Universität, Bratislava, und mit der Gold-Gedächtnismedaille der Comenius Universität in Bratislava ausgezeichnet.

\section{Bücher}

\section{Sigma-Tau und Roche schliessen ein wichtiges}

\section{Abkommen über Acetyl-L-Carnitin}

Die italienische FirmaSigma-Tau S.p.A. mit Sitz in Rom und $F$. Hoffmann-La Roche AG, Basel, haben soeben einen Vertrag unterzeichnet, der Roche das Recht auf die weltweite Registrierung und Vermarktung der Sigma-Tau-Wirksubstanz Acetyl-L-Carnitin einräumt. Der Vertrag regelt auch die künftige medizinische Entwicklung, die zum Teil mit weiteren Partnern von Sigma-Tau und mit Sigma-Tau selbst erfolgen wird. Das sehr gut verträgliche Arzneimittel auf Basis einer Natursubstanz hat in klinischen Studien der Phase II in Europa positive Wirkungen bei Patienten mit Alzheimer'scher Krankheit gezeigt.

In den USA wurde dieses Jahr an 27 Forschungszentren eine gross multizentrische Studie der Phase Il mit 400 Alzheimer-Patienten begonnen, die für ein Jahr mit AcetylL-Carnitin behandelt werden sollen. Daneben wurden in den USA zwe weitere klinische Prüfungen durchgeführt; die eine Studie an der $\mathrm{Col}$ umbia University, New York, wurde soeben fertiggestellt, die andere wird an der Stanford University, Palo Alto, Kalifornien, demnächst beendet. Als zusätzliche Einsatzgebiete für Acetyl-L-Carnitin werden gegenwärtig auch periphere Nervenschäden sowie Komazustände in tensiv erforscht.

\section{Roche und Organon schliessen Forschungsabkommen}

Organon International B.V., ein Geschäftszweig der Pharma Division von $A k z o$ in Oss, Niederlande, und die $F$. Hoffmann-La Roche AG in Basel haben ein Abkommen geschlossen, das künftig die gemeinsame Forschung und Entwicklung neuer Medikamente zur Behandlung von bestimmten psychischen Erkrankungen vorsieht. Die weltweiten Rechte an allen aus der geplanten Zusammenarbeit resultierenden Produkten werden sowohl von $R O$ che als auch von Organon wahrgenommen. Die beiden Unternehmen werden die gemeinsam entwickel-

\section{Bei der Redaktion eingetroffene Bücher}

\section{R.G. Wilkins}

'Kinetics and Mechanism of Reactions of Transition Metal Complexes'

2nd Thoroughly Revised Edition $\mathrm{VCH}$ Verlagsgesellschaft $\mathrm{mbH}$, Weinheim, 1991

GBF Monographs Volume 15

'Protein Glycosylation: Cellular. Biotechnological and Analytical Aspects'

Ed. by H.S. Conratd

VCH Verlagsgesellschaft $\mathrm{mbH}$,

Weinheim, 1991

\section{Personalia}

\section{Neue Mitglieder}

Jörg Herrmann

Dipl. Chem. ETH, Wartburgstrasse 16, 4663 Aarburg

Fabian Perroud

Dipl. Chem. HTL, Baderstrasse 6, 8400 Winterthur
S. Hauptmann

'Organische Chemie'

3., unveränderte Aufl.

Deutscher Verlag für Grundstoffindustrie $\mathrm{GmbH}$, Leipzig, 1991
Otmar Zoller

Dr. sc. nat. ETH, Schützenstrasse 33, 3097 Liebefeld 


\section{Institut für Polymere der ETH-Zürich}

Mittwoch 16.15 Uhr

Der Hörsaal CAB D28 befindet sich an der Universitätstrasse 6, dagegen ML II D28 im Maschinenlabor, Eingang Tannenstrasse!

22. Januar 1992 CAB D28

29. Januar 1992

CAB D28

5. Februar 1992 CAB D28

12. Februar 1992 ML II D28

19. Februar 1992 CAB D28

26. Februar 1992 CAB D28
Prof. Dr. W. Michaeli

Rheinisch-Westfälische Technische Hochschule, Aachen

'Notwendigkeiten und Chancen der Prozess-

Simulation in der Kunststoffverarbeitung'

\section{Prof. Dr. J. Schurz}

Karl-Franzens-Universität, Graz

'Rheologische Studien an Synovialflüssigkeiten'

Prof. Dr. H.-G. Kilian

Abt. Physik, Universität Ulm, Ulm

'Nichtlineares Zeitverhalten in Permanenten

Netzwerken als lineare Antwort im Sinne der

Thermodynamik Irreversibler Prozesse'

Dr. G. Riess

Ecole Nationale Supérieure de Chimie,

Mulhouse

'Anwendung von Blockcopolymeren als

Compatibilizer in Polymermischungen'

\section{Prof. Dr. C.W. Schläpfer}

Inst. für Anorg. Chemie, Univ. Fribourg, Fribourg

'Polymere als Liganden: die Komplexbildung PEI (Polyetherimine) mit Übergangsmetallionen'

Prof. Dr. G. Prota

Facultà di Science, Univ. di Napoli, Napoli

'The Chemistry of Melamine Skin Pigmentation' ten Produkte jedoch getrennt vermarkten. Die Zusammenarbeit betrifft die Erforschung von Serotonin, einer Substanz, die als Neurotransmitter für die Signalübertragung im Gehirn und anderen Organen wichtig ist. Neue Präparate aus der gemeinsamen pharmazeutischen Forschung sollen auf ihre mögliche Anwendung bei der Behandlung von Depressionen, Angstzuständen, Schizophrenie und verwandten Erkrankungen hin untersucht werden. Trotz der in den vergangenen Jahren erzielten Erfolge besteht noch genügend Raum für eine wesentliche Verbesserung in der Behandlung dieser Krankheiten.

Ehrungen

\section{Akademische Ehrungen}

Der Louisa Gross Horwitz Prize for Biology or Biochemistry 1991 der Columbia University wurde am 17. Oktober in New York den beiden ETH-Professoren Dr. Richard $R$. Ernst, Professor derETHZürich für Physikalische Chemie, und Dr. Kurt Wüthrich, Professor der ETH Zürich für Biophysik, verliehen für ihre Pionierbeiträge zur Entwicklung und Anwendung der Kernresonanzspektroskopie in der dreidimensionalen Strukturbestimmung biologischer Makromoleküle in Lösung.

Prof. Dr. Heinrich Zollinger, Professor der ETH Zürich im Ruhestand, wurde zum Honorary Fellow des Shenkar College of Textile
Technology and Fashion (Höhere Technische Lehranstalt Israels für alle Bereiche der Textiltechnologie) in Ramat-Gan, Israel, ernannt.

Daniel Bellus, Prof. Dr. Dipl.-Ing., Leiter des Konzernbereichs Forschung der Firma Ciba-Geigy $A G$, Basel, wurde in Anerkennung seiner 'originellen Beiträge zur industriellen organischen und bioorganischen Synthese sowie zur modernen Photochemie' mit der Ehrendoktorwürde der Slowakischen Technischen Universität, Bratislava, und mit der Gold-Gedächtnismedaille der Comenius Universität in Bratislava ausgezeichnet.

\section{Bücher}

\section{Sigma-Tau und Roche schliessen ein wichtiges}

\section{Abkommen über Acetyl-L-Carnitin}

Die italienische FirmaSigma-Tau S.p.A. mit Sitz in Rom und $F$. Hoffmann-La Roche AG, Basel, haben soeben einen Vertrag unterzeichnet, der Roche das Recht auf die weltweite Registrierung und Vermarktung der Sigma-Tau-Wirksubstanz Acetyl-L-Carnitin einräumt. Der Vertrag regelt auch die künftige medizinische Entwicklung, die zum Teil mit weiteren Partnern von Sigma-Tau und mit Sigma-Tau selbst erfolgen wird. Das sehr gut verträgliche Arzneimittel auf Basis einer Natursubstanz hat in klinischen Studien der Phase II in Europa positive Wirkungen bei Patienten mit Alzheimer'scher Krankheit gezeigt.

In den USA wurde dieses Jahr an 27 Forschungszentren eine gross multizentrische Studie der Phase Il mit 400 Alzheimer-Patienten begonnen, die für ein Jahr mit AcetylL-Carnitin behandelt werden sollen. Daneben wurden in den USA zwe weitere klinische Prüfungen durchgeführt; die eine Studie an der $\mathrm{Col}$ umbia University, New York, wurde soeben fertiggestellt, die andere wird an der Stanford University, Palo Alto, Kalifornien, demnächst beendet. Als zusätzliche Einsatzgebiete für Acetyl-L-Carnitin werden gegenwärtig auch periphere Nervenschäden sowie Komazustände in tensiv erforscht.

\section{Roche und Organon schliessen Forschungsabkommen}

Organon International B.V., ein Geschäftszweig der Pharma Division von $A k z o$ in Oss, Niederlande, und die $F$. Hoffmann-La Roche AG in Basel haben ein Abkommen geschlossen, das künftig die gemeinsame Forschung und Entwicklung neuer Medikamente zur Behandlung von bestimmten psychischen Erkrankungen vorsieht. Die weltweiten Rechte an allen aus der geplanten Zusammenarbeit resultierenden Produkten werden sowohl von $R O$ che als auch von Organon wahrgenommen. Die beiden Unternehmen werden die gemeinsam entwickel-

\section{Bei der Redaktion eingetroffene Bücher}

\section{R.G. Wilkins}

'Kinetics and Mechanism of Reactions of Transition Metal Complexes'

2nd Thoroughly Revised Edition $\mathrm{VCH}$ Verlagsgesellschaft $\mathrm{mbH}$, Weinheim, 1991

GBF Monographs Volume 15

'Protein Glycosylation: Cellular. Biotechnological and Analytical Aspects'

Ed. by H.S. Conratd

VCH Verlagsgesellschaft $\mathrm{mbH}$,

Weinheim, 1991

\section{Personalia}

\section{Neue Mitglieder}

Jörg Herrmann

Dipl. Chem. ETH, Wartburgstrasse 16, 4663 Aarburg

Fabian Perroud

Dipl. Chem. HTL, Baderstrasse 6, 8400 Winterthur
S. Hauptmann

'Organische Chemie'

3., unveränderte Aufl.

Deutscher Verlag für Grundstoffindustrie $\mathrm{GmbH}$, Leipzig, 1991
Otmar Zoller

Dr. sc. nat. ETH, Schützenstrasse 33, 3097 Liebefeld 


\section{Institut für Polymere der ETH-Zürich}

Mittwoch 16.15 Uhr

Der Hörsaal CAB D28 befindet sich an der Universitätstrasse 6, dagegen ML II D28 im Maschinenlabor, Eingang Tannenstrasse!

22. Januar 1992 CAB D28

29. Januar 1992

CAB D28

5. Februar 1992 CAB D28

12. Februar 1992 ML II D28

19. Februar 1992 CAB D28

26. Februar 1992 CAB D28
Prof. Dr. W. Michaeli

Rheinisch-Westfälische Technische Hochschule, Aachen

'Notwendigkeiten und Chancen der Prozess-

Simulation in der Kunststoffverarbeitung'

\section{Prof. Dr. J. Schurz}

Karl-Franzens-Universität, Graz

'Rheologische Studien an Synovialflüssigkeiten'

Prof. Dr. H.-G. Kilian

Abt. Physik, Universität Ulm, Ulm

'Nichtlineares Zeitverhalten in Permanenten

Netzwerken als lineare Antwort im Sinne der

Thermodynamik Irreversibler Prozesse'

Dr. G. Riess

Ecole Nationale Supérieure de Chimie,

Mulhouse

'Anwendung von Blockcopolymeren als

Compatibilizer in Polymermischungen'

\section{Prof. Dr. C.W. Schläpfer}

Inst. für Anorg. Chemie, Univ. Fribourg, Fribourg

'Polymere als Liganden: die Komplexbildung PEI (Polyetherimine) mit Übergangsmetallionen'

Prof. Dr. G. Prota

Facultà di Science, Univ. di Napoli, Napoli

'The Chemistry of Melamine Skin Pigmentation' ten Produkte jedoch getrennt vermarkten. Die Zusammenarbeit betrifft die Erforschung von Serotonin, einer Substanz, die als Neurotransmitter für die Signalübertragung im Gehirn und anderen Organen wichtig ist. Neue Präparate aus der gemeinsamen pharmazeutischen Forschung sollen auf ihre mögliche Anwendung bei der Behandlung von Depressionen, Angstzuständen, Schizophrenie und verwandten Erkrankungen hin untersucht werden. Trotz der in den vergangenen Jahren erzielten Erfolge besteht noch genügend Raum für eine wesentliche Verbesserung in der Behandlung dieser Krankheiten.

Ehrungen

\section{Akademische Ehrungen}

Der Louisa Gross Horwitz Prize for Biology or Biochemistry 1991 der Columbia University wurde am 17. Oktober in New York den beiden ETH-Professoren Dr. Richard $R$. Ernst, Professor derETHZürich für Physikalische Chemie, und Dr. Kurt Wüthrich, Professor der ETH Zürich für Biophysik, verliehen für ihre Pionierbeiträge zur Entwicklung und Anwendung der Kernresonanzspektroskopie in der dreidimensionalen Strukturbestimmung biologischer Makromoleküle in Lösung.

Prof. Dr. Heinrich Zollinger, Professor der ETH Zürich im Ruhestand, wurde zum Honorary Fellow des Shenkar College of Textile
Technology and Fashion (Höhere Technische Lehranstalt Israels für alle Bereiche der Textiltechnologie) in Ramat-Gan, Israel, ernannt.

Daniel Bellus, Prof. Dr. Dipl.-Ing., Leiter des Konzernbereichs Forschung der Firma Ciba-Geigy $A G$, Basel, wurde in Anerkennung seiner 'originellen Beiträge zur industriellen organischen und bioorganischen Synthese sowie zur modernen Photochemie' mit der Ehrendoktorwürde der Slowakischen Technischen Universität, Bratislava, und mit der Gold-Gedächtnismedaille der Comenius Universität in Bratislava ausgezeichnet.

\section{Bücher}

\section{Sigma-Tau und Roche schliessen ein wichtiges}

\section{Abkommen über Acetyl-L-Carnitin}

Die italienische FirmaSigma-Tau S.p.A. mit Sitz in Rom und $F$. Hoffmann-La Roche AG, Basel, haben soeben einen Vertrag unterzeichnet, der Roche das Recht auf die weltweite Registrierung und Vermarktung der Sigma-Tau-Wirksubstanz Acetyl-L-Carnitin einräumt. Der Vertrag regelt auch die künftige medizinische Entwicklung, die zum Teil mit weiteren Partnern von Sigma-Tau und mit Sigma-Tau selbst erfolgen wird. Das sehr gut verträgliche Arzneimittel auf Basis einer Natursubstanz hat in klinischen Studien der Phase II in Europa positive Wirkungen bei Patienten mit Alzheimer'scher Krankheit gezeigt.

In den USA wurde dieses Jahr an 27 Forschungszentren eine gross multizentrische Studie der Phase Il mit 400 Alzheimer-Patienten begonnen, die für ein Jahr mit AcetylL-Carnitin behandelt werden sollen. Daneben wurden in den USA zwe weitere klinische Prüfungen durchgeführt; die eine Studie an der $\mathrm{Col}$ umbia University, New York, wurde soeben fertiggestellt, die andere wird an der Stanford University, Palo Alto, Kalifornien, demnächst beendet. Als zusätzliche Einsatzgebiete für Acetyl-L-Carnitin werden gegenwärtig auch periphere Nervenschäden sowie Komazustände in tensiv erforscht.

\section{Roche und Organon schliessen Forschungsabkommen}

Organon International B.V., ein Geschäftszweig der Pharma Division von $A k z o$ in Oss, Niederlande, und die $F$. Hoffmann-La Roche AG in Basel haben ein Abkommen geschlossen, das künftig die gemeinsame Forschung und Entwicklung neuer Medikamente zur Behandlung von bestimmten psychischen Erkrankungen vorsieht. Die weltweiten Rechte an allen aus der geplanten Zusammenarbeit resultierenden Produkten werden sowohl von $R O$ che als auch von Organon wahrgenommen. Die beiden Unternehmen werden die gemeinsam entwickel-

\section{Bei der Redaktion eingetroffene Bücher}

\section{R.G. Wilkins}

'Kinetics and Mechanism of Reactions of Transition Metal Complexes'

2nd Thoroughly Revised Edition $\mathrm{VCH}$ Verlagsgesellschaft $\mathrm{mbH}$, Weinheim, 1991

GBF Monographs Volume 15

'Protein Glycosylation: Cellular. Biotechnological and Analytical Aspects'

Ed. by H.S. Conratd

VCH Verlagsgesellschaft $\mathrm{mbH}$,

Weinheim, 1991

\section{Personalia}

\section{Neue Mitglieder}

Jörg Herrmann

Dipl. Chem. ETH, Wartburgstrasse 16, 4663 Aarburg

Fabian Perroud

Dipl. Chem. HTL, Baderstrasse 6, 8400 Winterthur
S. Hauptmann

'Organische Chemie'

3., unveränderte Aufl.

Deutscher Verlag für Grundstoffindustrie $\mathrm{GmbH}$, Leipzig, 1991
Otmar Zoller

Dr. sc. nat. ETH, Schützenstrasse 33, 3097 Liebefeld 